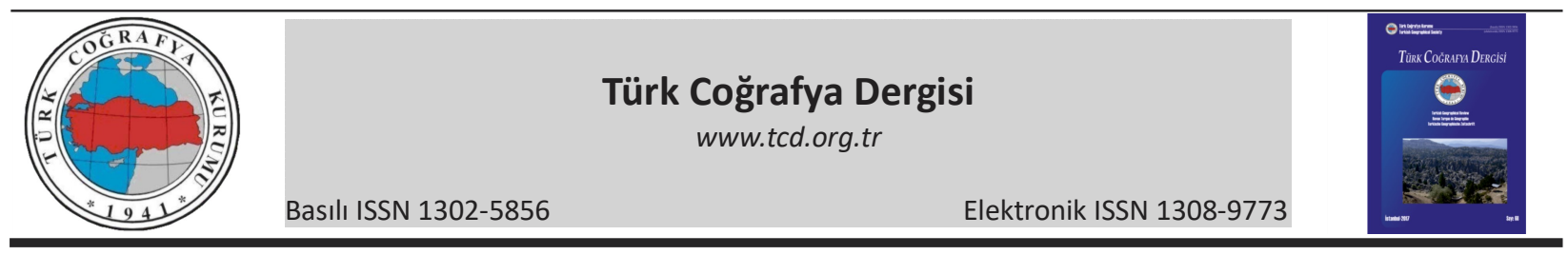

\title{
Gömülü objelerin 3-B modellenmesinde GPR/GPS kombinasyonu
}

\section{GPR / GPS combination in 3-D modeling of buried objects}

\author{
Celalettin Uçar a Füsun Balık Şanlı*a \\ ${ }^{a}$ Yıldız Teknik Üniversitesi, İnşaat Mühendisliği Fakültesi, Harita Mühendisliği Bölümü, İstanbul
}

\section{MAKALE BILGI}

Geliş/Received: 27.01.2017

Kabul/Accepted: 28.03.2017

Anahtar Kelimeler:

GPR

GPS

Topografik düzeltme

Keywords:

GPR

GPS

Topographic correction

*Sorumlu yazar/Corresponding author (F.B. Şanlı)fbalik@yildiz.edu.tr

http://dx.doi.org/10.17211/tcd.287481

\begin{abstract}
ÖZ / ABSTRACT
Bu çalışmanın amacı sığ jeofizik görüntüleme ve uzaktan algılama teknolojisi olan GPR yöntemini etkileyen parametrelerden topoğrafik değişkenliğin ölçme sonuçlarına etkisini belirlemek ve söz konusu GPR ölçmelerinde arazi eğiminin sebep olduğu sistematik olmayan hatanın ortadan kaldırılması problemine Geomatik/Harita Mühendisliği disiplini içerisinde ölçme tekniğinin güncel metot ve teknolojilerini kullanarak çözüm bulabilmektir. Günümüzde yaygın olarak kullanılan GPS teknolojisi ile elde edilecek topoğrafik verilerin GPR ölçmeleriyle eşzamanlı olarak toplanması ve birlikte yorumlanması ile GPR ölçmelerinde arazi eğiminden kaynaklanan hatanın giderilmesinin mümkün olduğu düşünülmektedir. Yerli veya yabancı literatürde GPR-GPS kombinasyonundan oluşan metodolojiyi konu alarak; Klasik GPR ölçme tekniği ile GPR-GPS kombinasyonunun, boyutları önceden bilinen gömülü referans obje üzerinden karşılaştırmalı olarak analiz edildiği herhangi bir akademik çalışma bulunmamaktadır. GPR - GPS kombinasyonundan oluşan metodun performansının test edilebilmesi için boyutları önceden bilinen gömülü obje referans alınarak klasik GPR ölçmeleri ile elde edilen 3D model ve GPR-GPS kombinasyonundan elde edilen 3D model, referans objenin gerçek boyutlarıyla karşılaştırılmıştı. Klasik GPR yöntemi sonuçları, GPR-GPS kombinasyonu sonuçlarıyla karşılaştırıldığında hem düz ve hem de eğimli arazide GPS-GPR yönteminin daha duyarlı yatay nokta konum hatası ürettiği belirlenmiş, yatay nokta konum hatasının eğimli arazi türünde $\% 28,2$ civarında küçüldüğü/iyileştiği gözlemlenmiştir.
\end{abstract}

The objective of this study is defining the effect of topographic slope differences, as being one of the parameters that affect GPR - a near surface geophysic and remote sensing technology, on measurement results, and to find out a solution to the problem of the unsystematic error resulted from slope area on GPR measurements with in the discipline of Geomatic Engineering by using recent survey methods and technologies. It is considered that it is possible to eliminate the errors resulted from area slope differences via GPS as being a widely used technology to acquire topographic data, by collecting and evaluating the relevant data simultaneously. Taking into consideration the methodology that objects the combination of GPR-GPS in local and foreign literature; there is not such an academic attempt to study the combination of GPR-GPS comparatively with classical GPR survey technique, thorough the buried reference object of which dimensions are known in advance. In order to test the performance of the method derived from the combination of GPR-GPS combination, buried object, of which dimensions are known in advance, will be considered as a reference, then two models of 3D; one 3D model that is provided by classical GPR survey sand another $3 D$ model that is provided by the combination of GPR-GPS, was compared with the actual dimensions of the object. When comparing the results of the traditional GPR survey with those of the GPR-GPS combination, it has been noted that the GPR-GPS method produced beter horizontal point positioning precision, and the horizontal positioning uncertainty was improved about $28,2 \%$ for slope land types.

\section{Giriş}

Gömülü boru ve araçların güvenli ve doğru pozisyonlarının belirlenmesinde, yol durum incelemesi ve güçlendirme çalışmalarında, köprülerde ve havaalanı pistlerinde, binaların yapısal denetimlerinin sağlanması gibi çok geniş alanlarda kullanılmakta olan bir teknoloji olarak GPR, her geçen gün kelimenin tam anlamıyla milyonlarca insanın güvenliğini sağlayan hayati bir teknik haline gelmiştir. GPR'ın diğer önemli uygulama alanları; mayın arama ve boşluk tespiti gibi gömülü potansiyel tehlikeleri içerirken jeolojik oluşumların ve buzul ortamların araştırılması, arkeolojik alanların keşfedilmesi, tanımlanması ve kazı öncesinde konumlandırılmaları, yeraltındaki insan kalıntlarının ve silahların bulunması gibi adli tıp araştırmalarını da içerir. GPR her ne kadar geniş kullanım alanlarına sahip olsa da 
bu tekniğin başarılı bir şekilde uygulanabilmesi arka planındaki bilimsel temellerin iyi anlaşılmasını ve her bir uygulama alanına özel olarak yüksek düzeyde uzmanlığı gerektirmektedir (Perciso, 2014).

Son otuz yıl içerisinde elektronik endüstrisinde yaşanan gelişmeler, zahmetli ve pahalı bir iş olan ışık hızı ölçümlerinin daha ucuz, kolay ve daha duyarlı yapılmasını sağlamıştır. Işık hızının duyarlı ölçümlerinin sonucunda yeraltında ışık hızına yakın hareket eden elektromanyetik dalgaların daha hassas ve nanosaniye mertebesinde ölçülmesini ve sığ jeofizik araştırmalarda doğru sonuçlara ulaşılmasını sağlamıştır. Bu çalışmalar ve gelişmeler GPR uygulamalarını doğurmuştur. GPR ilk önce buz kalınlığının ölçülebilmesi için geliştirilmiştir. Normal yer ortamında yapılan çalışmalarda elde edilen verilerin sismik yöntemlerde kullanılan veri işleme teknikleri ile işlenmesi sonucunda 10 $20 \mathrm{~m}$ gibi araştirma derinliğine ulaşıldığı görülmüştür. Günümüzde ise GPR yöntemi sığ yer araştırmaları ile arkeometri çaIışmalarında yaygın olarak kullanılmaktadır. Madencilik ve jeolojik çalışmalarda 1970'li yıllarda kullanılmaya başlanan GPR, 1980'li yıllarda iyi ayrımlılık veren $500 \mathrm{MHz}-1 \mathrm{GHz}$ antenlerle doğal soğurmanın daha az olduğu sığ incelemeler için kullanılmıştır. Bu çalışmalar içerisinde arkeolojik çalışmaları da bulmak mümkündür. 1990'larda ise düşük (10, 20 ve $50 \mathrm{MHz}$ ) ve yüksek (2,5-3 GHz) merkez frekanslı antenler kullanılmıştır. Daha sonra GPR, maden arama, stratigrafi, yol kaplama denetlemesi, yapı, inşaat, su arama vs. gibi alanlarda da kullanılmaya devam etmiştir (Alp vd., 2003).

GPR metodu; dalgalar halindeki elektromanyetik palslerin yer içinde yayılımına ve dalganın seyir süreci boyunca radar antenine geri yansıyan sinyallerin zamanın bir fonksiyonu olarak kaydedilmesi esasına dayanır. Yeraltındaki her fiziksel veya kimyasal değişim, radar sinyali derinlere indikçe enerjisinin bir kısmının yüzeye geri yansımasına sebep olur. Bu süreç sinyalin enerjisi tamamen tükenene kadar devam eder. Yer içi katmanlarındaki süreksizliğin meydana getirdiği yansıma, kaya, tortu, toprak, bunların su içerikli çeşitli karışımları, taş veya kaya yapısındaki değişiklikler veya stratigrafik ara yüzeylerin kitlesel yoğunluk farklılıkları gibi yansıtıcı yüzeylerin elektriksel ve manyetik özelliklerindeki değişimlere bağlı olarak oluşur. Radar yansımaları, radar enerjilerinin yeraltı katmanları arasında arkeolojik yapılar ve etraflarını çevreleyen yığınlardan geçerken üretilirler. Yeraltındaki ortam boyunca karşılaşılan mezar, tünel, gömü veya boru gibi gömülü yapılar radar dalgalarının yayılma hızlarında değişikliklere neden olduklarından belirgin radar yansımaları üretirler. Birbirine çakışık haldeki çok sayıda dalga formu aynı lokasyonda yeraltından farklı derinliklerde yansıyan bir dizi halinde kaydedilirler. Buna o lokasyona ait radar yansıma izi denilir (Davis ve Annan, 1989; Harrari, 1996; Van Dam ve Schlager, 2000).

Piyasada bulunan çoğu üretici firmanın GPR ürünleri; tek kişi ile kullanılabilen, GPR kontrol ünitesi, güç kaynağı ve tamamı tekerlekler üzerine konuşlandırılmış anten ünitelerinden oluşan sistemlerdir. Yeraltı yansımaları; yansımaların düşey görüntüsünü oluşturmak için hangi veri elde etme yönteminin kullanıldığına bakılmaksızın, çift yollu seyir zaman veya hız değeri biliniyorsa yansıma verisinin yaklaşık derinliğini düşey eksende ifade ederken, ölçüldüğü noktanın yeryüzündeki konumunu ise yansıma verisinin kaydedildiği noktanın profil başlangıcına olan mesafesini yatay eksende olacak şekilde gösterilirler (Dannowsky, 1999; Grandjean ve Gourry, 1999).
Eğer ölçme bölgeleri arasında kayda değer düzeyde yükseklik farklııkları varsa yansıma veri kayıtlarındaki yüzeysel düzensizlikten kaynaklanan bu hata topografik düzeltmeyle giderilir. Yer yüzeyinin eğimli, engebeli, pürüzlü veya topografik yüksekliklerinin ölçüm profili boyunca sık değiştiği durumlarda yeralt radar yansıma verilerine ölçümlerden sonraki veri işleme aşamasında bir düzeltme getirilmelidir. Yüzeyin belirgin şekilde düzensiz olduğu durumlarda ise yükseklik ölçümleri belki de her bir metrede bir veya daha da sık olacak şekilde yapılmalıdır (Sun ve Young 1995, Davisand Annan, 1989). GPR sistemleri veri işleme aşamasında kayıtlı radar yansıma izlerinin tümünü spesifik olarak belirlenen yeryüzü referans noktasından itibaren cihazın ölçmeyi yaptığı lokasyonun mesafesini ölçmek için bir tekerlek veya benzeri bir aletle veri toplayacak şekilde programlanmışlardır (Lehman ve Green 1999; Green vd., 2003).

Cismin üzerinden geçerken yüzeydeki anten tarafindan kaydedilen gömülü objeye ait çok sayıdaki yansıma izleri bir yansıma hiperbolü oluşturur. Klasik GPR tekniğinde gömülü obje ya da katmanın radargram üzerinde tespit edildiği nokta; yalnızca başlangıç ve bitiş noktaları bilinen ölçüm profilinin başlangıcından itibaren "Ölçüm Tekerleği" ile ölçülendirilmiş mesafe ve derinlik değeriyle ifade edilen iki boyutlu lokal bir koordinat sistemine göre tanımlıdır (Green vd., 2003). Bu durumda tekerlek devir sayısı ile ölçülen mesafe Şekil 1'de gösterildiği gibi planimetrik (yataya indirgenmiş) mesafeden fazladır. Bu hata klasik GPR Modelinin başlangıç noktasından itibaren kat edilen mesafeyi ifade eden yatay ekseninde ölçek hatasına neden olmaktadır.

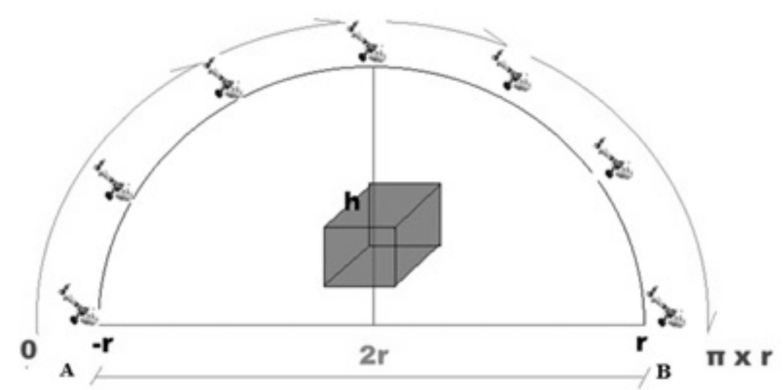

\section{$2 r \neq \pi \times r$}

$(\pi=3,14)$

Objenin planimetrik konumu= $r$

Objenin Klasik GPR radargram konumu= $\mathrm{r} \times(3,14 / 2)$

Şekil 1. Profil başlangıç noktası A ile profil bitiş noktası B arasındaki "Planimetrik" koordinatlarla hesaplanan yataya indirgenmiş mesafe $(2 r)$ ve GPR Ölçüm Tekerleği ile ölçülen mesafe $((2 \pi \times r) / 2)$ gösterilmektedir.

Figure 1. The distance between the first location $(A)$ and the final location ( $B$ ) of the profile is presented as $(2 r)$ and $((2 \pi \times r) / 2)$ for planimetric calculations and GPR measurements, respctively.

Analitik geometriye göre koordinatları bilinen iki nokta arasındaki yatay mesafe;

$$
[\mathrm{AB}]=\sqrt{\left((\mathrm{X} 2-\mathrm{X} 1)^{2}+(\mathrm{Y} 2-\mathrm{Y} 1)^{2}\right)}
$$

eşitlik (1) ile hesaplanabilir. Yataya indirgenmiş mesafenin elde edilmesi; GPR ile eşzamanlı yapılan GNSS/GPS ölçümleri ile mümkündür. Bu sayede her radar yansıma izi (trace), GPR anteninin yer yüzeyinde yer alt katmanlarına dair verileri topladığı konumda kaydedilen GNSS/GPS verisi ile X,Y ve Z koordinat olarak tanımlanmış olacaktır. 
Jeofizikçilere göre yansıma hiperbollerinin varlığı veri yorumlama aşamasında dikkat dağıtıcı bir etkendir çünkü gömülü objenin gerçek konumunu ifade etmemektedir. Bu hiperboller, yeraltında yayılan radar enerjisinin izlediği yolun kompleks geometrisinin ürünüdürler. Öte taraftan hiperbollerin varlığı bazen verilerin yorumlanmasına yardımcı da olabilir, çünkü yansıma profillerinde kolaylıkla tanımlanabilen yeraltı objelerinin geometrilerini ve spesifik boyutlarını gösterirler. En önemlisi hız analizlerinde hızın belirlenmesine olan katkısı görmezden gelinemez. Doğru bir hız analizi ise ancak yansıma hiperbollerinin doğru geometride üretilmiş olması ile mümkündür (Conyers., 2013).

"Ground Penetration Radar and Application" adlı kitabının "GPR Archaeometry" bölümünde Japonyanın Saitobaru, Miyazaki bölgesinde topografyanın kayda değer derecede değişken olduğu, yer yer 25 derecelik eğim değerlerinin görüldüğü bir ortamda tarihi mezar odasının tespiti için yapılan arkeolojik araştırmada topografik düzeltmenin uygulanabilmesi için anten eğimine bağlı bir düzeltmenin getirilmesi gerektiği ve ancak bu sayede yeraltındaki yapıların doğru şekilde görüntülenebileceği anlatılmaktadır. Anten eğimi düzeltmesi ve topografik düzeltme yapıldıktan sonra radargram verilerinin mezar odasının gerçek şeklini ve boyutlarını ifade etmekte olduğu belirtilmektedir (Jol , 2009).

Kayda değer bir eğimin olmadığı ortamlar için radar yansımalarının düşey varsayıldığı klasik GPR metodu yeterli olmaktadır. Ancak topografik değişikliklerin büyük oranda olduğu yüksek eğimli arazilerde yapılacak çalışmalarda klasik GPR metodu yetersiz kalmaktadır. Topografyanın değişken olduğu alanlarda GPR araştırmaları için 2006 yılında Goodman ve ark. tarafindan arazi eğimini dikkate alan statik düzeltme konusunda ilk iyileştirmeler yapılmıştır. Fakat bu ilk araştırmalarda eğim ölçer bir mekanizma kullanılmadan arazinin sabit bir eğimde olduğu varsayılmıştır. Sonraki yıllarda GPR profilinin eğimini ölçen tiltmetreler bazı ekipmanlarda standart olarak sunulmaya başlanmış ve GPR taramaları ile senkronize şekilde kullanılmış olsa da konu ile ilgili yayımlanmış hiçbir makalenin bulunmadığı Goodman D. ve Piro S. (2013) tarafindan belirtilmiştir.

\section{Amaç ve Kullanılan Yöntem}

Araştırma Klasik GPR ölçümünden farklı olarak GNSS-GPS verilerinin eşzamanlı kaydedilmesi ve GPR/GPS Veri Tabanı ile işlenmesi esasına dayanmaktadır. Bu amaçla, $250 \mathrm{Mhz}$ merkez frekansında MALA ProEx serisi GPR ünitesi, Trimble RS8 GNSS/GPS alıcısı ile senkronize veri kaydının yapılabilmesi için PC tabanlı "Twedge" datalogger, GPR verilerinin işlenmesinde ve yorumlanmasında "Reflex-W", veri tabanının oluşturulması amacıyla Microsoft Access, 3 boyutlu çizim ve modelleme aşamalarında NetCAD ve AutoCAD Civil-3D yazılımlarından yararlanılmıştır.

\subsection{GPR/GPS Veri Tabanı}

GPR/GPS Veri tabanı Microsoft Access yazılımı kullanılarak oluşturulmuştur. GPS ve GPR radargramından UTM koordinat hesaplanmak istenilen detay noktalar olmak üzere 2 tablo içermektedir. GPR ile eşzamanlı kaydedilen GNSS/GPS verilerinin bulunduğu tablolar GPR/GPS Veri Tabanı kullanılarak en- tegre edilmiştir (Şekil 2).

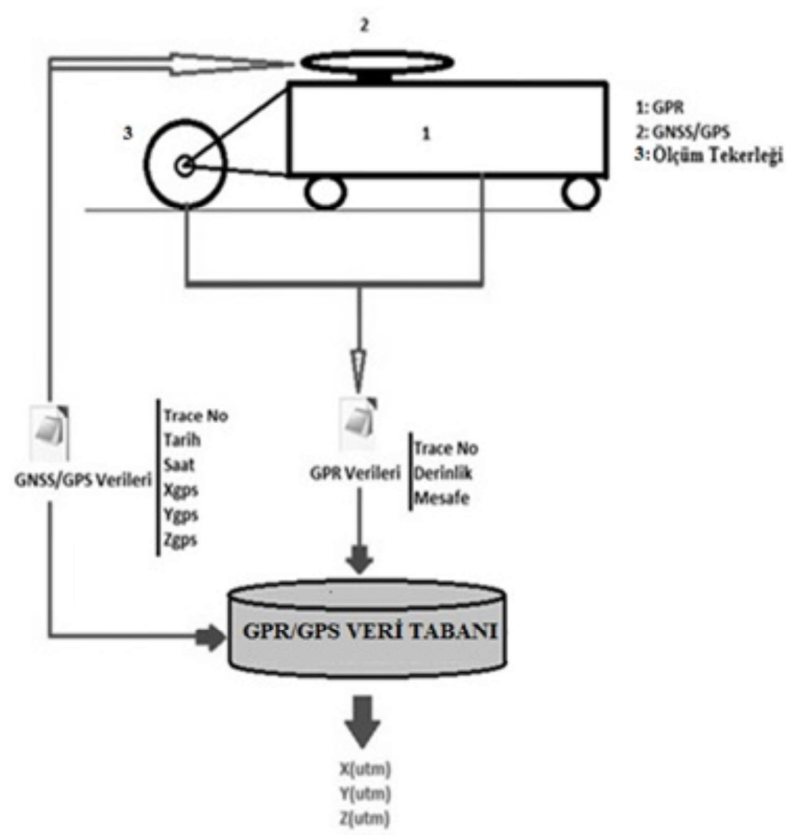

Şekil 2. (1)GPR, (2)GPS, (3) Ölçüm Tekerleği (Odometer) kısımları olmak üzere; GPS ve GPR radargramından işaretlenen detay noktalarına ait karşılıklı verilerin yer aldığı 2 tablonun senkronize edildiği ve entegrasyonun sağlanıp verilerin işlendiği GPR/GPS Veri Tabanı gösterilmektedir.

Figure 2. GPR/GPS Data Base which performs data sencronization, integration and processing steps between the sample points table (which picked from GPR radargram) and GPS table of corresponding points. (1)GPR, (2) GPS, (3) (Odometer) are the parts of the system.

\section{Tablolar:}

Tablo 1'de GNSS/GPS ölçüleri ile eşzamanlı yapılan GPR ölçümü "Reflex-W" programı kullanılarak zamansal senkronizasyonla entegre edilmiş ve ".cor" uzantılı dosya üretilmiştir. ".cor" uzantılı dosya Microsoft Excel yazılımı kullanılarak tablo haline getirilir (Tablo 1'de 17418 yansıma izi (trace) kaydından 10 adedi gösterilmektedir).

Tablo 1. GPS verileri tablosu.

Table 1. Table of GPS data.

\begin{tabular}{|l|l|l|l|l|l|l|}
\hline Trace & Tarih & Saat & Y koordinatı & X koordinatı & Z koordinatı & Anten $(\mathbf{H})$ \\
\hline 1 & 8.10 .2016 & $12: 51: 30$ & 425250.781 & 4533906.124 & 4.19 & 1.2 \\
\hline 12 & 8.10 .2016 & $12: 51: 31$ & 425250.769 & 4533906.101 & 4.23 & 1.2 \\
\hline 13 & 8.10 .2016 & $12: 51: 31$ & 425250.757 & 4533906.077 & 4.23 & 1.2 \\
\hline 14 & 8.10 .2016 & $12: 51: 31$ & 425250.744 & 4533906.054 & 4.23 & 1.2 \\
\hline 15 & 8.10 .2016 & $12: 51: 31$ & 425250.732 & 4533906.031 & 4.23 & 1.2 \\
\hline 16 & 8.10 .2016 & $12: 51: 31$ & 425250.720 & 4533906.007 & 4.23 & 1.2 \\
\hline 51 & 8.10 .2016 & $12: 51: 32$ & 425250.695 & 4533906.011 & 4.27 & 1.2 \\
\hline 52 & 8.10 .2016 & $12: 51: 32$ & 425250.665 & 4533906.025 & 4.27 & 1.2 \\
\hline 53 & 8.10 .2016 & $12: 51: 32$ & 425250.635 & 4533906.038 & 4.27 & 1.2 \\
\hline 54 & 8.10 .2016 & $12: 51: 32$ & 425250.606 & 4533906.052 & 4.27 & 1.2 \\
\hline
\end{tabular}

GPR/GPS (2) Kombinasyon Metodu uygulamasında GPS anteninin GPR ünitesine dikey pozisyonda sabitlenmiş olduğu varsayılmaktadır. GPR verileri 2 boyutlu radargramlarla ifade edilir. Radargramlar yorumlanırken nokta hedefler yada katman sınırlarını tanımlayabilmek için "pick" adı verilen işaretlemeler yapılır. İşaretlenen her nokta için Trace No (yansıma izi numarası), profil başlangıcından olan mesafe ve genlik değerleri gibi veriler kullanıcının tercihine göre dijital olarak kaydedilebilir. 
Radargram üzerinde gerçek koordinatı hesaplanmak istenilen noktalar işaretlenmiş ve Trace No, derinlik ve mesafe bilgileri GPR/GPS Veri Tabanında işlenmek üzere kaydedilmiştir (Tablo 2).

Tablo 2. GPR radargramın da işaretlenerek UTM koordinat hesaplanmak istenen detay noktaları tablosu.

Table 2. The table of detail points, picked on radargram, for which the UTM coordinate is to be calculated.

\begin{tabular}{|l|l|l|}
\hline Trace No & Derinlik & Mesafe \\
\hline 1 & 0.774 & 1.125 \\
\hline 12 & 0.720 & 1.725 \\
\hline 13 & 0.684 & 2.275 \\
\hline 14 & 0.927 & 2.825 \\
\hline 15 & 0.964 & 3.225 \\
\hline 16 & 1.045 & 4.1 \\
\hline 51 & 1.054 & 4.7 \\
\hline 52 & 1.081 & 5.65 \\
\hline 53 & 1.144 & 6.125 \\
\hline 54 & 1.279 & 6.85 \\
\hline
\end{tabular}

GPR radargramın da işaretlenen (pick) detay noktaları Trace No, Derinlik ve Profil başlangıcından itibaren ölçülen mesafe seçilerek ".txt" uzantılı dosya olarak kaydedilir. Radargram üzerinde işaretlenen nokta verilerinin ".txt" uzantılı bu kaydı Microsoft Excel yazılımı kullanılarak tablo haline getirilir ve kaydedilir. Tablo 1 ve Tablo 2, aynı yansıma izi (trace) numarasına tanımlı GPS ile GPR radargramında işaretlenen nokta verilerini entegre etmek amacıyla Trace No sütunu birincil anahtar olarak kullanılmak üzere ilişkilendirilir. Her "trace_no" için yalnızca bir GPS verisi ve yalnızca bir işaretlenen nokta kaydı bulunduğundan eşleşmede herhangi bir hata oluşmaz (Şekil 3).

Tablolar arası ilişkiler:

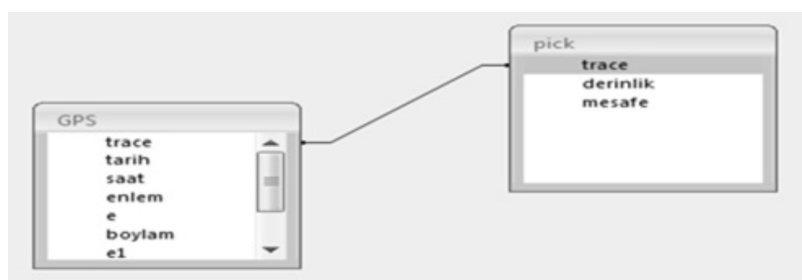

Şekil 3. GPR/GPS veri tabanı ilişkilerinin kurulması.

Figure 3. Relations of GPR/GPS database.

\section{Veri Entegrasyonu:}

GPS ve işaretlenen nokta tablolarının ilişkilendirilmeleri ve oluşturulan veri tabanı sorgusu sonucunda işaretlenen her nokta için bu iki tablo verilerinin entegrasyonu sağlanır (Tablo 3).

\section{işlem Adımları:}

Aşağıda izah edilen işlem adımlarının tamamı GPR/GPS veri tabanı tarafindan gerçekleştirilmektedir. Tüm hesaplamalar "GPS Sorgu1" alanları kullanılarak SQL kodlarla hazırlanmıştır. Fakat daha kolay anlaşılabilmesi adına veri entegrasyonundan sonra yapılacak işlem adımları Microsoft Excel sütun adlarıyla isimlendirilerek ayrıca formüle edilecektir. Sunulan eklerdeki indekste her veri grubu için Microsoft Excel tablosunda karşılık gelen alan adları gösterilmektedir (Ek 1).

Açıklık Açısı Hesabı:

Manyetik kuzey ile radar profilinin yer yüzeyi üzerinde taşındığı doğrultu arasındaki açıdır (Şekil 4).

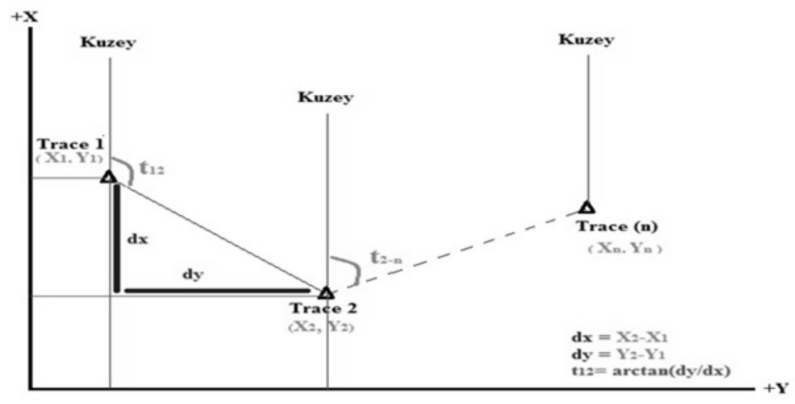

Şekil 4. Açıklık açısı.

Figure 4. Azimuth.

Trace1 ve Trace2 nolu ölçüm noktaları (Yansıma İzi Noktaları) arasındaki bazın manyetik kuzeyle yaptı̆ı açı; t12 görülmektedir. Gömülü objeye dair seçilen detay noktalarını Ülke Koordinat Sisteminde konumlandırabilmek için açıklık açısının mutlaka bilinmesi gerekir. Açıklık açısı hesabı; arctan: (dy/dx) eşitliği ile hesaplanır. dy (Y koordinatları farkı) ve dx (X Koordinatları farkı) pozitif veya negatif olması durumlarına göre 4 farklı şekilde hesaplanır (Ek 1).

Her bir yansıma izi (Trace) için dy, dx ve arctan (dy/dx) değerleri tanımlanmalıdır. Profil başlangıcından itibaren GPS (2) anteninin tanımlı olduğu koordinat sisteminin X ekseni üzerindeki yer değiştirme miktarı " $\mathrm{dx}$ " ve profil başlangıcından itibaren GPS (2) anteninin tanımlı olduğu koordinat sisteminin Y ekseni üzerindeki yer değiştirme miktarı "dy" ile ifade edilir (EK 1).

1. açıklık açısının hesaplanması ile GPR'ın yeryüzündeki profil güzergahının manyetik kuzeyle yaptığı açı matematiksel olarak

Tablo 3. Veri entegrasyonu tablosu.

Table 3. Data integration table.

\begin{tabular}{|c|c|c|c|c|c|c|c|c|}
\hline Trace & Tarih & Saat & Y koordinatı & X koordinatı & Z koordinatı & anten $(\mathbf{H})$ & Derinlik & Mesafe \\
\hline 1 & 8.10 .2016 & $12: 51: 30$ & 425250.781 & 4533906.124 & 4.19 & 1.2 & 0.774 & 1.125 \\
\hline 12 & 8.10 .2016 & $12: 51: 31$ & 425250.769 & 4533906.101 & 4.23 & 1.2 & 0.720 & 2.275 \\
\hline 13 & 8.10 .2016 & $12: 51: 31$ & 425250.757 & 4533906.077 & 4.23 & 1.2 & 0.684 & 2.825 \\
\hline 14 & 8.10 .2016 & $12: 51: 31$ & 425250.744 & 4533906.054 & 4.23 & 1.2 & 0.927 & 3.225 \\
\hline 15 & 8.10 .2016 & $12: 51: 31$ & 425250.732 & 4533906.031 & 4.23 & 1.2 & 0.964 & 4.1 \\
\hline 16 & 8.10 .2016 & $12: 51: 31$ & 425250.720 & 4533906.007 & 4.23 & 1.2 & 1.045 & 4.7 \\
\hline 51 & 8.10 .2016 & $12: 51: 32$ & 425250.695 & 4533906.011 & 4.27 & 1.2 & 1.054 & 5.65 \\
\hline 52 & 8.10 .2016 & $12: 51: 32$ & 425250.665 & 4533906.025 & 4.27 & 1.2 & 1.081 & 6.85 \\
\hline 53 & 8.10 .2016 & $12: 51: 32$ & 425250.635 & 4533906.038 & 4.27 & 1.2 & 1.144 & 8.25 \\
\hline 54 & 8.10 .2016 & $12: 51: 32$ & 425250.606 & 4533906.052 & 4.27 & 1.2 & 1.279 & 6.85 \\
\hline
\end{tabular}


ifade edilmiş olur. Başlangıç noktasının X (başlangıç) ve $\mathrm{Y}$ (başlangıç) koordinatları, açıklık açısı ve başlangıçtan itibaren profil üzerindeki yatay mesafesi bilinen bir noktanın $X$ ve $Y$ koordinatları eşitlik (2) ve eşitlik (3) ile hesaplanır.

$X_{n}=\left(X_{\text {başlangıç }}\right)+(L$ başlangıç noktasından itibaren yatay mesafe $)$ $x \cos \left(t_{\text {Açiklik Açıs }}\right)$

$\mathrm{Y}_{\mathrm{n}}=\left(\mathrm{Y}_{\text {başlangıç }}\right)+(\mathrm{L}$ başlangıç noktasından itibaren yatay mesafe $)$

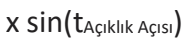

Gömülü objeyi doğru konumlandırabilmek için öncelikli olarak GPR'ın yer yüzeyindeki konumu bilinmelidir. Dolayısıyla her yansıma izi (trace) için GPR'ın yeryüzündeki konumunu ifade eden YGPS ve XGPS değerlerinin doğru hesaplanması gerekir. Fakat veri entegrasyonunda yaşanan senkronizasyon problemi nedeni ile bazı ardışık yansıma izi (trace) numaraları için aynı GPS koordinatları görülebilmektedir. GPR her 0,025 metrede bir (örnekleme aralığı programlanarak değiştirilebilmektedir) yansıma izi üreterek çok hızlı şekilde veri toplarken GPS aynı serilikte koordinat üretememektedir. Bu problem çözülmezse ardışık $Y$ ve $X$ koordinatları arasında fark olmayacağından dolayı açıklık açısı hesaplanamayacak ve sistem hata verecektir. Bu nedenle eğer $\mathrm{Y}$ ve $\mathrm{X}$ koordinatları farkı $=0$ ise; koordinatların ardışık olarak aynı seyrettiği bu alanlar için seçilen detay noktaları tablosunda her yansıma izi için tanımlanan başlangıçtan itibaren "mesafe" ölçümü yataya indirgenerek YGPS ve XGPS koordinatları özel olarak hesaplanmalıdır.

GPS tablosunda aynı koordinat değerinde kaydedilen yansıma noktalarını yeniden koordinatlandırmak için ölçüm tekerleğinden alınan mesafe değeri kullanılır. İlk verilere göre aynı koordinatta tanımlanan yansıma izi noktaları için koordinatlar yeniden hesaplanır (Ek 2).

GPR ölçümü ile eşzamanlı yapılan GPS ölçümleri ve yukarıda açıklanan adımlar sonucunda GPR radargramı üzerinde tanımlı olan yansıma izlerinin tamamına ait XGPS, YGPS, ZGPS koordinatları hesaplanmıştır. GPS verilerinden elde edilen " $Z$ " koordinatından anten yüksekliği ve seçilen detay noktasının derinlik değeri kullanılarak yükseklik değeri Z elipsoidal koordinat değeri belirlenmiştir (sırasıyla anten yüksekliği ve derinlik değeri alanları J ve $\mathrm{N}$ alan adları ile Ek 2'de tanımlanmıştır).

\subsection{Arazi Çalışmalarının Planlanması}

Çalışmanın birinci amacı boyutları önceden bilinen gömülü obje üzerinde Klasik GPR ile GPR/GPS Kombinasyon Metodunu karşılaştrmak, konum verilerinin modellemeye olan etkilerini araştırmaktır. Ölçüm profili üzerinde yansıma izleri (trace) arası mesafe ölçümü odometre ile yapılan Klasik GPR yönteminin GPS ile kombinasyonu sayesinde profil mesafesinin planimetrik koordinatlarla yataya indirgenmesini sağlamak ve oluşan model verilerini gömülü objenin bilinen boyutlarıyla karşılaşttrmaktır. Bu amaçlar doğrultusunda İstanbul ilii, Maltepe ilçesi, Orhangazi Şehir Parkında bulunan gömülü su depoları çalışma alanı olarak seçilmiştir (Şekil 5).

Söz konusu park 2010-2013 yılları arasında İstanbul Büyükşehir Belediyesi tarafindan deniz dolgusu ile oluşturulmuştur. Gömülü su depoları deniz dolgusu tamamlandıktan sonra inşa edilmiştir. Aynı boyutta ve yan yana olan 3 su deposu ile 1 makine dairesi bulunmaktadır. Mimari ve statik olmak üzere tüm proje detayları, aplikasyon noktaları mevcuttur. Dolayısıyla gö- mülü su depolarının geometrik boyutları detaylı olarak bilinmektedir. Profil hatları oluşturulurken gömülü su depolarının bilinen aplikasyon koordinatları göz önüne alınarak mümkün olduğunca şev eğimlerini de içerecek şekilde fazladan ölçü alınmasına özen gösterildi. Dolayısıyla Şekil 6'da gösterilen 1, 2, 27, 28,29 ve 46 nolu profiller su depolarının oturum alanının dışındadır. Ölçümlerden sonra GPS koordinatları referansıyla oluşan profiller Şekil 7'de sunulmaktadır.

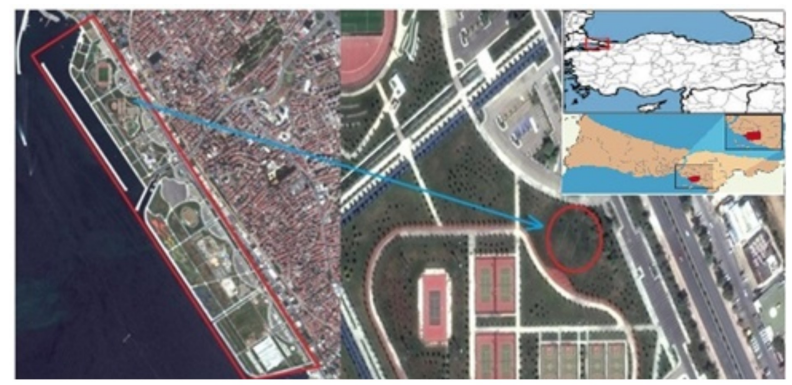

Şekil 5. Maltepe Orhangazi Şehir Parkı ve gömülü su depoları. Figure 5. Maltepe Orhangazi Park and buried water tanks.

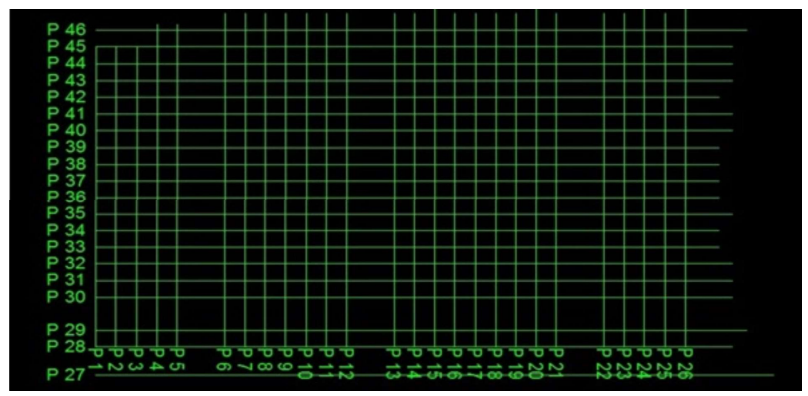

Şekil 6. GPR ölçme modeli.

Figure 6. GPR surveying model.

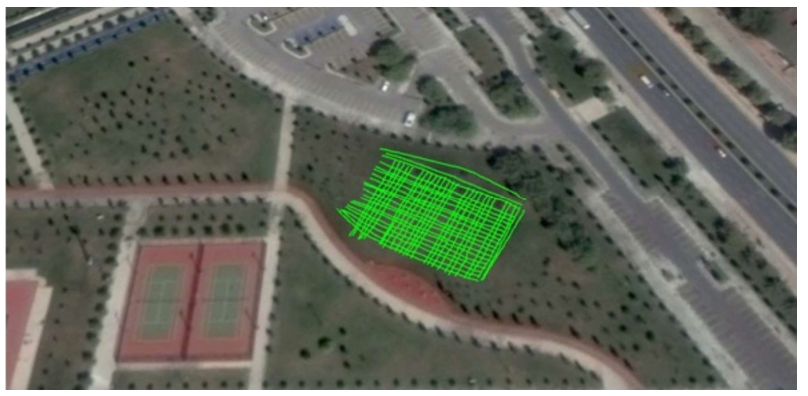

Şekil 7. GPR ölçüm profilleri.

Figure 7. GPR surveying profiles.

\subsection{Arazi Çalışmaları}

Maltepe Orhangazi Şehir parkında bulunan 3'lü su depolarının bulunduğu alanda 46 ölçüm profili için 1-26 numaralı profiller düşey, 27-46 kesitler diğerlerine dik şekilde yatay olarak aplike edildi. Tüm jeofizik ölçümler tam otomatik Mala marka ProEx serisi GPR donanımı ve kontrol ünitesi, 250Mhz merkez frekanslı kapalı antenlerle gerçekleştirilmiştir (Şekil 8).

İ.B.B Anadolu Yakası Park ve Bahçeler Müdürlüğünden alınan çalışma izni şartları göz önünde bulundurularak yersel işaretleme yapılmadı. Yatay ve düşey GPR Ölçüm Profillerinin baş- 
langıç noktasını belirleyen aks için 50 metrelik çelik şerit metre zemine yerleştirildi. Profiller çelik şerit metre aksının her 1.5 metrede bir olacak şekilde mümkün olduğu kadar lineer doğrultularla ölçüldü (Şekil 7). Profillerin toplam uzunluğu 1714,2 metredir. Veri senkronizasyonunun sağlanması amacıyla "Twedge" datalogger yazılımı kablosuz (bluetooth) bağlant kurularak kullanıldı. Aynı sistem saati ile kaydedilen GPR ve GPS ölçümleri bu sayede eşzamanlı GPR/GPS okumaları olarak gerçekleştirilmiştir.

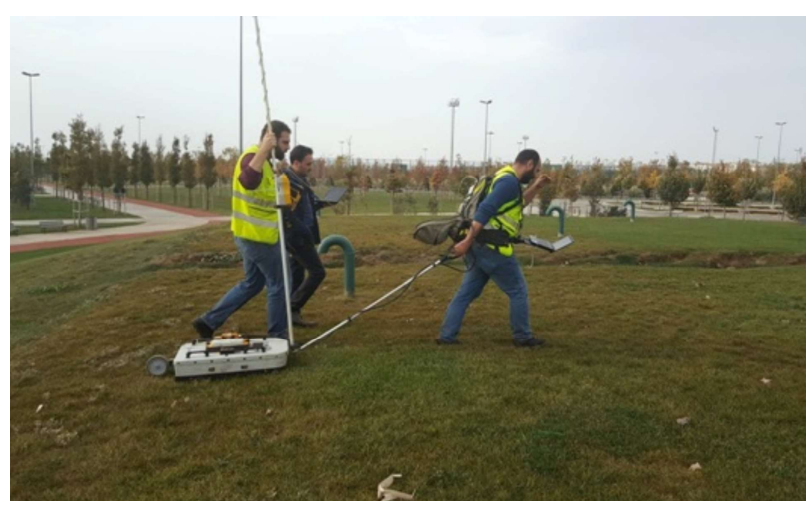

Şekil 8. GPR profillerinin ölçümü.

Figure 8. GPR surveying.

\subsection{Laboratuvar Çalışmaları}

\section{GPR Profillerinin Iş̧lenmesi:}

Arazide toplanan GPR verisi, ofis ortamında değerlendirilerek yeraltı oluşumlarının karakteristiklerini gösteren kesit haritaları görsel olarak tanımlanabilir duruma ve yorumlamaya açık hale getirilmiştir. Arazide uygulanan ölçümlerin maruz kaldığı EM gürültü etkileri (araç sinyalleri, cep telefonları, telsiz vericileri, v.b. diğer istenmeyen dış etkiler) çeşitli filtreler kullanılarak temizlenmiştir. İşlenen 2 boyutlu (2B) GPR profilleri ilk olarak kendi içlerinde değerlendirilip yorumlanmış ve sonrasında koordinatlarıyla birleştirilerek 3 boyutlu (3B) yeralt haritalarına çevrilmiştir. Veri işleme kısmında, arazide uygulanan GPR yöntemi ile elde edilen radar profilleri işlenerek ayrı ayrı incelenmiştir. Oluşturulan her GPR profili için sırasıyla aşağıdaki işlem adımları dikkatli bir şekilde gerçekleştirilmiştir. İşlenen radargramlarla "Reflex-W" yazılımı kullanılarak oluşturulan 3-B model Şekil 9'da görülmektedir. Yüzeyden itibaren $10 \mathrm{~cm}$ de bir alınan kesitlerden 8 numaralı kesitte gömülü depo sınırları görüntülenmektedir.

(A) Hava/yansıma/topografik düzeltmesi (Static Correction)

(B) Yüksek geçişli gürültü filtrelemesi (Dewow)

(C) Zaman sınırlaması (Time Cut)

(D) Dalga genlik yükseltme filtrelemesi (Gain Function)

(E) Frekans bandı geçişi (Background Removal)

(F) Hız Düzeltmesi

\section{Yüksek Genlikli Anomalilerin Işaretlenmesi:}

Önceki bölümde anlatıldığı şekilde işlenen radargramlar da arzu edilen anomaliler GPR/GPS veri tabanında işlenmek üzere işaretlenerek kaydedildi. Bu aşamada Reflex-W yazııımının genlik ölçeği kullanılarak yüzeye en yakın ve en yüksek genlikli anomaliler işaretlendi. Bu yüksek genlikli anomali araştırmaya konu olan gömülü su depolarının betonarme sınırlarıdır. 12000 ile

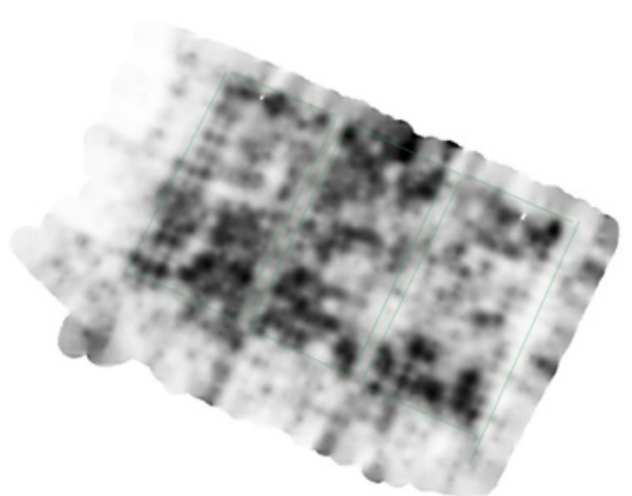

Şekil 9. Reflex-W yazılımı kullanılarak oluşturulan 3-B modelde 8 No'lu kesit (Slice). (Yüzeyden 0,75-0,80 cm derinlikte bulunan kesitte gömülü su depolarının sınırları görülmektedir).

Figure 9. A slice of 3-D model generated with "Reflex-W" software. The boundaries of the buried water tanks at the depth of $0.75-0.80 \mathrm{~cm}$ from the surface are visible).

15000 genlik değerine sahip olan tabaka diğer anomalilerden kolaylıkla ayırt edilebilir durumdadır. Genlik değerlerindeki +/işaret değişikliği polarite farklılaşmasından oluşmaktadır ve işaretten bağımsız olarak en yüksek genlik değeri su depolarının betonarme zeminini ve tavan sınırlarını ifade etmektedir. Bu yüksek genlikli anomalilerin radargram profilleri üzerinde işaretlenmesi "Reflex-W" yazılımı kullanılarak 46 profil için ayrı ayrı yapılmış ve ".pck" uzantılı (pick) işaret dosyası olarak "trace no", "derinlik" ve "mesafe" verileri ile kaydedilmiştir. Bu adımların sonunda araştırmaya konu olan su depolarının Klasik GPR modeli oluşturulmuştur.

GPR/GPS Kombinasyon Metodu ile Elde Edilen Modelin Oluşturulması:

GPR/GPS kombinasyonu modelinde yansıma izi (trace) noktaları arası mesafelerin ölçümünde GPR ölçümü ile eşzamanlı yapılan GPS okumalarından elde edilen ".cor" uzantılı dosyada bulunan kartezyen koordinat verileri kullanılır. Bu sayede klasik GPR metodunda odometre (ölçüm tekerleği)'nin devir sayısına göre mesafe belirlemenin arazinin eğimli olduğu durumlarda neden olduğu sistematik olmayan hatanın giderilmesi ve mesafe ölçülerinin planimetrik koordinatlar kullanılarak yataya indirgenmeleri sağlanır. Ayrıca profil hatt boyunca arazinin kot farklılıkları "Z" koordinat verisi kullanılarak topografik düzeltme sağlanmış olur. Bu amaçla $250 \mathrm{Mhz}$ merkez frekansında Mala Pro-Ex GPR ünitesi Trimble GPS donanımı ile entegre edilmiştir. Veriler profil başlangıcından profil bitiş noktasına kadar her profil için GPR ünitesi ile senkronize şekilde kaydedilmiştir. GPS verilerinin bulunduğu ".cor" uzantlı dosyada ki konum verileri Coğrafi Koordinat Sistemindedir $(\phi, \lambda)$. Dolayısıyla modelleme yapabilmek ve düzeltme değerlerini koordinat verilerine uygulayabilmek amacıyla bu verilerin tamamı 3 derecelik Universal Transvers Mercator (Ülke Koordinat Sistemi)'a çevrilmiştir. Senkronize GPR ve GPS kayıtları GPR/GPS veri tabanında yüksek genlikli anomali sınırlarının işaretlendiği her bir yansıma izi için eşzamanlı GPS veri kayıtlarından elde edilen "Trace No", "X koordinat", "Y koordinat", "Z koordinat", "Anten Yüksekliği” verileri ile GPR profillerinden işaretlemelerle kaydedilen "Trace No" ve "Derinlik" verileri eşleştirilerek GPR/GPS kombinasyon modeli oluşturulmuştur. 


\section{Bulgular}

Bu bölümde sırasıyla Klasik GPR metodu, GPR/GPS Kombinasyon Metodu ile hazırlanan 2 model boyutları bilinen gömülü obje ile karşılaştırılmıştır. Daha önce de ifade edildiği gibi Maltepe Orhangazi Parkında bulunan gömülü su depoları ve bilinen boyutları her iki modelin kıyaslanması açısından referans olarak kullanılmıştır (Şekil 10).

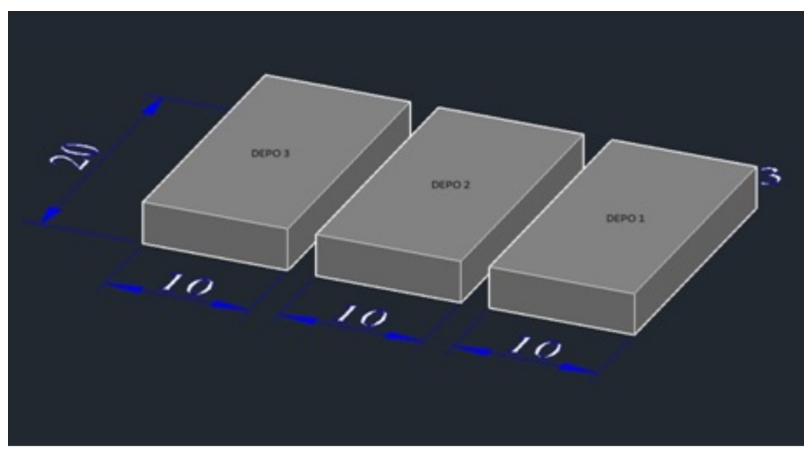

Şekil 10. Gömülü su depolarının 3-B modeli. Figure 10. 3-D Model of buried water tanks.

Ölçmenin gerçekleştirildiği alanda 20 metre uzunluğunda ve 10 metre genişliğinde 3 ayrı depo gömülü vaziyettedir. Depolar arasında 2 metre boşluk bulunmaktadır. Üst kotu 3,45m ve temel beton seviyesi -0,2 m'dir. İnşaat safhasından itibaren imalatları kontrol edilip fotoğraflanmıştır (Şekil 11).

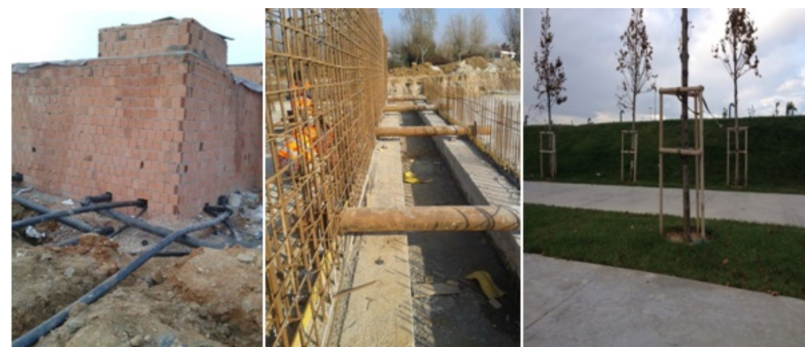

Şekil 11. Gömülü su depolarının imalat safhasına ve imalat sonrasına ait görünümler.

Figure 11. Views of buried water tanks during the construction phase and up to date.

3.1. Klasik GPR Modeli ile GPR-GPS Kombinasyon Modellerinin Boyutları Bilinen Gömülü Obje ile Karşılaştırılması

\section{Geometrik Analiz 1:}

Düşey yönlü ölçümlerden biri olan 22 No'lu profilde su deposu betonarme duvarlarının radargramda oluşturduğu yüksek genlikli anomaliler ve bu anomaliler üzerinde yapılan işaretlemeler Şekil 12'de görüldüğü gibidir. Siyah çizgi izi klasik GPR modelini, Mavi çizgi GPR/GPS Kombinasyon Modelini temsil etmektedir (Şekil 13). 3 No'lu depo üzerinden algılanan bu anomalinin Klasik GPR metoduna karşılık geldiği Şekil 13'de görülebilir.

Arazi eğiminin başladığı andan itibaren GPR/GPS Kombinasyon Modeli (Mavi) Klasik GPR Modelinden (Siyah) ayrılarak depo sınırları ile kıyaslandığında gömülü objeyi daha doğru ifade etmekte, azalmakta olan kot değeri ile birlikte depo sınırlarına daha yakın bir görünüm sergilemektedir.

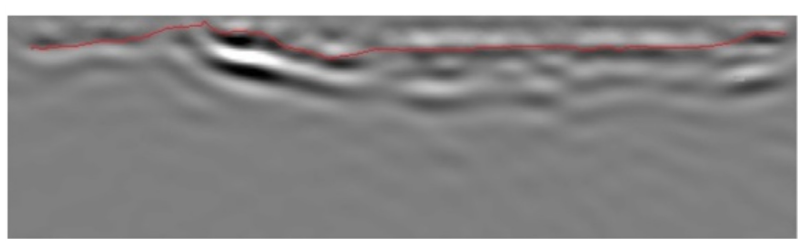

Şekil 12. 22 No'lu radargram ve yüksek genlikli anomalilerin işaretlenmesi. Figure 12. High amplitude anomalies are picked on radargram 22.

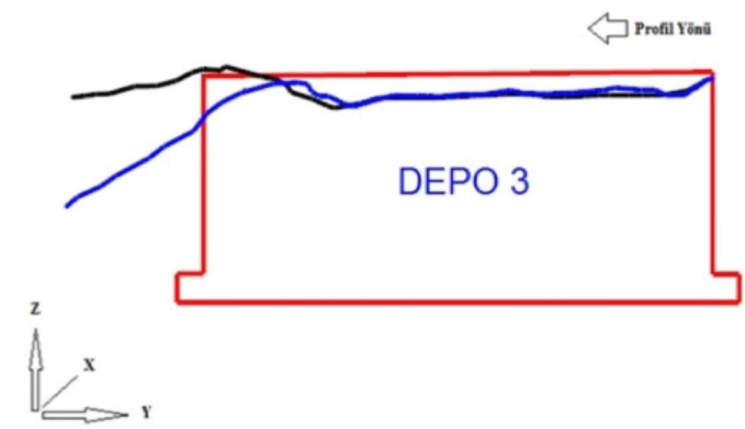

Şekil 13. 3 No'lu depo üzerinde yapılan 22 No'lu ölçüm profilinin her iki modelle kıyaslanması görülmektedir.

Figure 13. Comparison of profile 22, lying on the 3rd water tank, on both models.

\section{Geometrik Analiz 2:}

Her 3 depo sınırını da içeren yatay yönlü ölçüm profillerinden biri olan 36 nolu radargram ve depo sınırlarını ifade eden yüksek genlikli anomali işaretlemeleri Şekil 14'de sunulmaktadır.

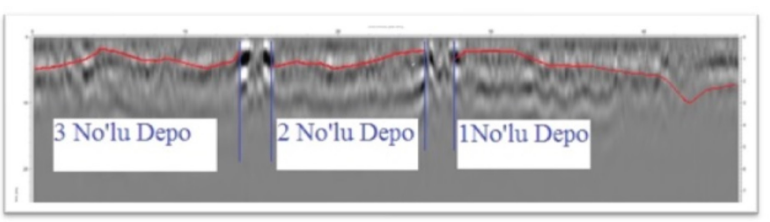

Şekil 14. 36 No'lu radargram üzerinde yüksek genlikli anomalilerin işaretlenmesi.

Figure 14. High amplitude anomalies picked on radargram which is gathered from 36th profile.

1, 2 ve 3 No'lu depolar arasındaki yüksek genlikli düşey yönlü saçılma depolar arasındaki boşlukları ifade etmektedir. Depo sınırlarını ifade eden yüksek genlikli anomalide yapılan işaretleme noktaları kullanılarak Klasik GPR, GPR/GPS Modellerine ait nokta dosyaları üst kotu 3,45 m olan su deposu sınırları ile koordinatlı şekilde çakıştırılmıştır (Şekil 15).

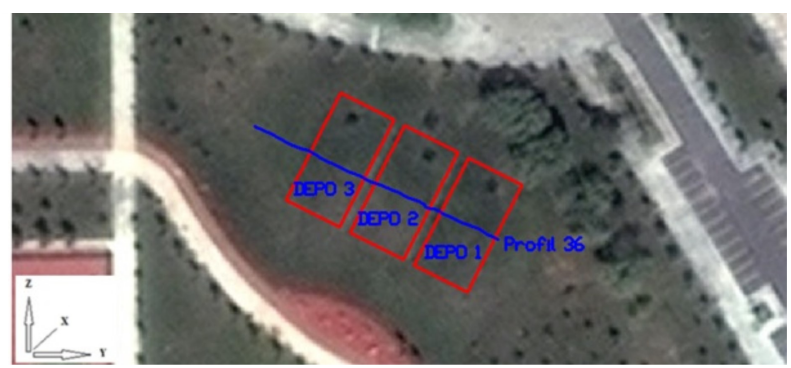

Şekil 15. 36 No'lu profilde işaretlenen yüksek genlikli yansıma anomalilerinin Klasik GPR, GPR/GPS Kombinasyonu Modellerine dair noktaların aplikasyonu. Figure 15. Sample points application of high amplitude anomalies, obtained from each Classical GPR and GPR/GPS combination models, picked on profile 36 
Modelin $Y, X$ ve $Z$ eksenlerine NetCAD çizim programı "Hesap" Menüsünde bulunan Nokta Editörü yardımıyla eksen transformasyonu uygulanmış ve Şekil 16 'daki görünümü elde edilmiştir.

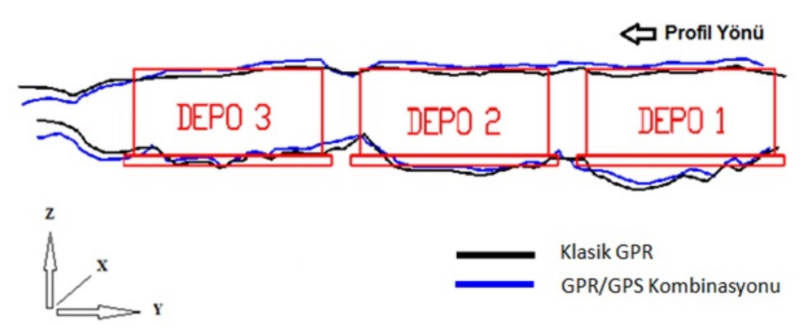

Şekil 16. 36 No'lu profilde işaretlenen yüksek genlikli yansıma anomalilerinin Klasik GPR ve GPR/GPS Kombinasyonu Modellerine dair koordinatlı noktalarının kesit görünümü.

Figure 16. View of high amplitude anomalies with sample points from classical GPR and GPR/GPS combination models for profile 36.

Şekil 16'da görülen siyah çizgi Klasik GPR, mavi çizgi GPR/GPS Kombinasyon modelini tasvir etmektedir. Depolar arası boşlukların olduğu bölüme bakıldığında her iki yöntemde de yüzey ve zemin eğrileri birbirine yaklaşmaktadır. Eğriler arazi eğiminin olmadığı düzlemsel bir zemin altında gömülü olan 2 nolu depo üzerinde neredeyse çakışık bir vaziyette iken 3 nolu depo sınırlarında farklılaşmaktadır. Şekil 13'de görüldüğü gibi eğimli arazide klasik GPR eğrilerinden ayrılarak depo sınırlarına daha yakın bir profil sergileyen GPR/GPS Kombinayon Modeli gömülü obje sınırlarını daha doğru ifade etmektedir. Tüm profillerde görsel olarak analiz edildiğinde iki model arasında depo sınırlarına en yakın olan eğri GPR/GPS Kombinayon Modelini ifade eden mavi çizgidir.

Sayısal Analiz 1:

1 ve 2 No'lu örneklerde Klasik GPR Metodu ile kıyaslandığında GPR/GPS Metodunun daha başarılı olduğu görülmektedir. Bu iki yöntemden hangisinin daha doğru bir modelleme imkanı sağladığını gösterebilmek amacıyla her iki yönteme dair detay noktaları, nokta konumları kıyaslanarak analiz edilmiştir. 3 ayrı su deposu sınırlarının tam olarak üzerinde bulunan 41 No'lu ölçüm profili ve Klasik GPR, GPR/GPS Kombinasyon Modeli olmak üzere her iki modele dair detay noktaları koordinatlı olarak sunulmaktadır (Şekil 17).

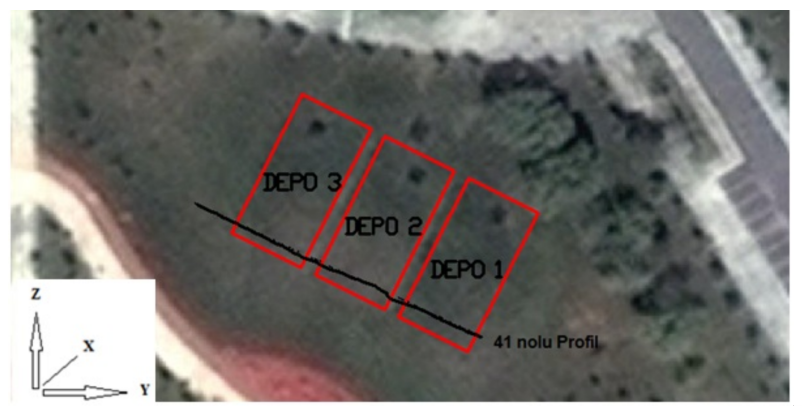

Şekil 17. 41 No'lu ölçüm profili için Klasik GPR, GPR/GPS olmak üzere her iki modele ait detay noktaları.

Figure 17. Sample points of classical GPR and GPR/GPS combination models for profile 41.

Modelin Y, X ve Z eksenlerine NetCAD çizim programı "Hesap" Menüsünde bulunan Nokta Editörü yardımıyla eksen transformasyonu uygulanmış ve Şekil $18^{\prime}$ de sunulan kesit görünümü elde edilmiştir. Şekil 18'de görülen siyah çizgi Klasik GPR, mavi çizgi GPR/GPS Kombinasyon Modelini ifade etmektedir. Depolar arası boşlukların olduğu bölüme bakıldığında her iki yöntemde de yüzey ve zemin eğrileri birbirine yaklaşmaktadır. 41 No'lu profil ölçüm profilleri arasında arazi eğiminin bulunduğu 1 ve 3 No'lu su depoları arasında en yüksek eğime sahiptir. 2 ve 3 No'lu depolar arasında bulunan boşluk kısmı yaklaşık 0,4 $\mathrm{m}$ kadar çökmüş olduğundan topografik düzeltmenin ve dolayısıyla GPR/GPS Kombinasyon Modelinin etkisinin en net görülebileceği örnektir. GPR/GPS Kombinasyon Modelini ifade eden mavi çizgi incelendiğinde 2 ve 3 No'lu depolar arasındaki çöküntü bölümünde yüksek eğim değerleri kaydedildiğinden bu noktalarda diğer modelden farklılaşmakta ve depo sınırlarına bariz şekilde yaklaşmaktadır. 3 No'lu depo üzerinde arazi eğiminden kaynaklanan topografik değişiklikler GPR/GPS Kombinasyon Modelinin başarısını öne çıkarmaktadır (Şekil 19).

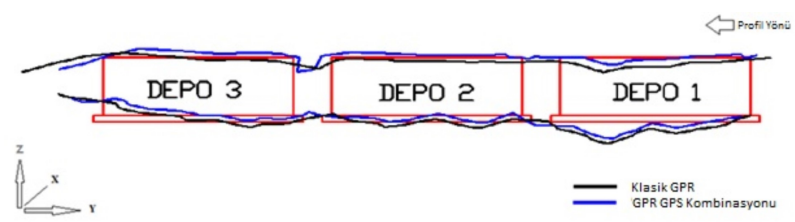

Şekil 18. 41 No'lu ölçüm profili için Klasik GPR, GPR/GPS olmak üzere her iki modele ait detay noktalarının kesit görünümü.

Figure 18. Side view of sample points for Profile 41, generated with both GPR and GPR/GPS combination methods.

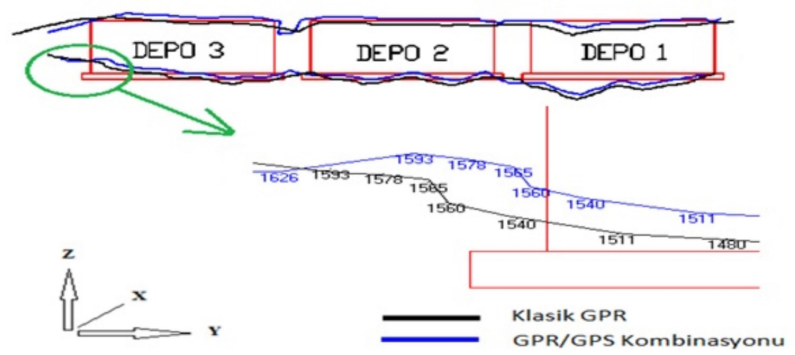

Şekil 19. 41 nolu Profil 3 No'lu su deposu üzerinde artan arazi eğiminin neden olduğu topografik değişiklikler ve GPR/GPS Kombinasyon Modelinin modellemeye olan katkısı.

Figure 19. Topographic changes caused by increasing land slope for profile 41, on the water tank 3 boundries, and the success of the GPR / GPS Combination Model on the buried object modeling.

Aynı radargram üzerinden alınan örneklemeler olmasına karşılık Klasik GPR Modelini ifade eden 1593 No'lu siyah nokta ile GPR/GPS modelini ifade eden 1593 No'lu mavi renkli nokta kIyaslandığında; GPR/GPS kombinasyonu sayesinde elde edilen planimetrik mesafenin yatayda 0,56 m, düşeyde 0,16 m ötelenerek depo sınırlarına daha yakın bir konuma taşındığı görülmektedir. Benzer durum Şekil 19'da görüldüğü gibi 1578, 1565, 1560 ve 1540 numaralı detay noktaları için de geçerlidir. Bu bölümde söz konusu eğimli arazi detay noktaları ile arazi eğimi bulunmayan 511, 539, 553, 566 No'lu detay noktaları için gömülü su depolarının bilinen koordinatları kullanılarak modellemenin istatistiksel başarısı araştrılmıştır. 41 No'lu profil hattının 1 No'lu depo ile kesişim noktasının koordinatları hesaplamalarda "ümit değer" olarak kullanılmıştr. Tablo 4'de eğimsiz arazi için seçilen detay noktalarının gömülü deponun bilinen koordinatlarına göre standart sapma hesabı görülmektedir. Bilinen nokta koordinatları "ümit değer" kabul edilerek detay noktaların koordinat değerleri ile farkları olan gerçek hata, varyans 
Tablo 4. Eğimsiz arazide Klasik GPR ve GPR/GPS Modelleri için standart sapma hesabı.

Table 4. Standard deviation calculation for Classic GPR and GPR/GPS Combination Models on a flat ground.

\begin{tabular}{|c|c|c|c|c|c|c|c|c|c|c|c|c|c|c|}
\hline $\mathrm{NN}$ & $\mathrm{xi}$ & yi & \begin{tabular}{|l|} 
Klasik GPR X \\
\end{tabular} & $-d x$ & $-d x^{\wedge 2}$ & Klasik GPR Y & $-d y$ & $-d y^{\wedge} 2$ & GPR/GPS X & $-d x$ & $-d x^{\wedge} 2$ & GPR/GP5Y & -Dy & $-d \gamma^{\wedge} z_{2}$ \\
\hline Ümit Değer & 4533983.398 & 425246.057 & & & & & & & & & & & & \\
\hline 85 & & & 4533983.096 & 0.302 & 0.091 & 425247.071 & -1.014 & 1.028 & 4533983.096 & 0.302 & 0.091 & 425247.071 & -1.014 & 1.028 \\
\hline 86 & & & 4533983.103 & 0.295 & 0.087 & 425247.047 & -0.990 & 0.980 & 4533983.103 & 0.295 & 0.087 & 425247.046 & -0.989 & 0.979 \\
\hline 87 & & & 4533983.110 & 0.288 & 0.083 & 425247.023 & -0.966 & 0.933 & 4533983.111 & 0.287 & 0.083 & 425247.022 & -0.965 & 0.930 \\
\hline 88 & & & \begin{tabular}{|l|l}
453983.117 \\
\end{tabular} & 0.281 & 0.079 & 425246.999 & -0.942 & 0.887 & 4533983.118 & 0.280 & 0.078 & 425246.997 & -0.940 & 0.883 \\
\hline 89 & & & \begin{tabular}{|l|}
4533983.124 \\
\end{tabular} & 0.274 & 0.075 & 425246.975 & -0.918 & 0.843 & 4533983.125 & 0.273 & \begin{tabular}{|l|l|}
0.074 \\
\end{tabular} & 425246.972 & -0.915 & \begin{tabular}{|l|l|}
0.837 \\
\end{tabular} \\
\hline 90 & & & 4533983.131 & 0.267 & 0.071 & 425246.951 & -0.894 & 0.799 & 4533983.132 & 0.266 & 0.071 & 425246.947 & -0.890 & 0.793 \\
\hline 91 & & & 4533983.139 & 0.259 & 0.067 & 425246.927 & -0.870 & 0.757 & 4533983.140 & 0.258 & 0.067 & 425246.923 & -0.866 & 0.749 \\
\hline 92 & & & 4533983.146 & 0.252 & 0.064 & 425246.903 & -0.846 & 0.716 & 4533983.147 & 0.251 & 0.063 & 425246.898 & -0.841 & 0.707 \\
\hline 93 & & & 4533983.153 & 0.245 & 0.060 & 425246.879 & -0.822 & 0.676 & 4533983.154 & 0.244 & 0.059 & 425246.873 & -0.816 & 0.666 \\
\hline 94 & & & 4533983.160 & 0.238 & 0.057 & 425246.855 & -0.798 & 0.637 & 4533983.162 & 0.236 & 0.056 & 425246.849 & -0.792 & 0.627 \\
\hline 95 & & & \begin{tabular}{|l|l}
4533983.167 \\
\end{tabular} & 0.231 & 0.053 & 425246.831 & -0.774 & 0.599 & \begin{tabular}{|l|l}
4533983.169 \\
\end{tabular} & 0.229 & 0.053 & 425246.824 & -0.767 & 0.588 \\
\hline 96 & & & 4533983.174 & 0.224 & 0.050 & 425246.807 & -0.750 & 0.563 & 4533983.176 & 0.222 & 0.049 & 425246.799 & -0.742 & 0.551 \\
\hline 97 & & & 4533983.181 & 0.217 & 0.047 & 425246.783 & -0.726 & 0.527 & 4533983.183 & 0.215 & 0.046 & 425246.775 & -0.718 & 0.515 \\
\hline 98 & & & \begin{tabular}{|l|l}
433983.188 \\
\end{tabular} & 0.210 & \begin{tabular}{|l|l|}
0.044 \\
\end{tabular} & 425246.759 & -0.702 & 0.493 & \begin{tabular}{|l|}
4533983.191 \\
\end{tabular} & 0.207 & 0.043 & 425246.750 & -0.693 & 0.480 \\
\hline 99 & & & 4533983.195 & 0.203 & 0.041 & 425246.735 & -0.678 & 0.460 & 4533983.198 & 0.200 & 0.040 & 425246.725 & -0.668 & 0.446 \\
\hline 100 & & & \begin{tabular}{|l|l}
4533983.202 \\
\end{tabular} & 0.196 & 0.038 & 425246.711 & -0.654 & 0.428 & 4533983.205 & 0.193 & 0.037 & 425246.700 & -0.643 & 0.414 \\
\hline 101 & & & 4533983.209 & 0.189 & 0.036 & 425246.687 & -0.630 & 0.397 & 4533983.212 & 0.186 & 0.034 & 425246.676 & -0.619 & 0.383 \\
\hline 102 & & & 4533983.216 & 0.182 & 0.033 & 425246.663 & -0.606 & 0.368 & 4533983.220 & 0.178 & 0.032 & 425246.651 & -0.594 & 0.353 \\
\hline 103 & & & \begin{tabular}{|l|l}
433983.223 \\
\end{tabular} & 0.175 & 0.030 & 425246.639 & -0.582 & 0.339 & 4533983.227 & 0.171 & 0.029 & 425246.626 & -0.569 & 0.324 \\
\hline 104 & & & 4533983.230 & 0.168 & 0.028 & 425246.615 & -0.558 & 0.312 & 4533983.234 & 0.164 & \begin{tabular}{|l|}
0.027 \\
\end{tabular} & 425246.602 & -0.545 & 0.297 \\
\hline 105 & & & 4533983.238 & 0.160 & 0.026 & 425246.591 & -0.534 & 0.285 & 4533983.241 & 0.157 & 0.025 & 425246.577 & -0.520 & 0.270 \\
\hline 106 & & & 4533983.245 & 0.153 & 0.024 & 425246.567 & -0.510 & 0.260 & 4533983.249 & 0.149 & 0.022 & 425246.552 & -0.495 & 0.245 \\
\hline 107 & & & 4533983.252 & 0.146 & 0.021 & 425246.543 & -0.486 & 0.237 & 4533983.256 & 0.142 & 0.020 & 425246.528 & -0.471 & 0.221 \\
\hline 108 & & & 4533983.259 & 0.139 & 0.019 & 425246.519 & -0.462 & 0.214 & 4533983.263 & 0.135 & 0.018 & 425246.503 & -0.446 & 0.199 \\
\hline 109 & & & 4533983.266 & 0.132 & 0.017 & 425246.495 & -0.438 & 0.192 & 4533983.271 & 0.127 & 0.016 & 425246.478 & -0.421 & 0.177 \\
\hline 110 & & & 4533983.273 & 0.125 & 0.016 & 425246.471 & -0.414 & 0.172 & 4533983.278 & 0.120 & 0.014 & 425246.453 & -0.396 & 0.157 \\
\hline 111 & & & 4533983.280 & 0.118 & 0.014 & 425246.447 & -0.390 & 0.152 & 4533983.285 & 0.113 & 0.013 & 425246.429 & -0.372 & 0.138 \\
\hline 112 & & & 4533983.287 & 0.111 & 0.012 & 425246.423 & -0.366 & 0.134 & 4533983.292 & 0.106 & 0.011 & 425246.404 & -0.347 & 0.120 \\
\hline 113 & & & 4533983.294 & 0.104 & 0.011 & 425246.399 & -0.342 & 0.117 & 4533983.300 & 0.098 & 0.010 & 425246.379 & -0.322 & 0.104 \\
\hline 114 & & & 4533983.301 & 0.097 & 0.009 & 425246.375 & -0.318 & 0.101 & 4533983.307 & 0.091 & 0.008 & 425246.355 & -0.298 & 0.089 \\
\hline 115 & & & 4533983.308 & 0.090 & 0.008 & 425246.352 & -0.295 & 0.087 & 4533983.314 & 0.084 & 0.007 & 425246.330 & -0.273 & 0.075 \\
\hline 116 & & & 4533983.315 & 0.083 & 0.007 & 425246.328 & -0.271 & 0.073 & 4533983.321 & 0.077 & 0.006 & 425246.305 & -0.248 & 0.062 \\
\hline 117 & & & 4533983.323 & 0.075 & 0.006 & 425246.304 & -0.247 & 0.061 & 4533983.329 & 0.069 & 0.005 & 425246.281 & -0.224 & 0.050 \\
\hline 124 & & & \begin{tabular}{|l|}
4533983.374 \\
\end{tabular} & 0.024 & 0.001 & 425246.136 & -0.079 & 0.006 & 4533983.337 & 0.061 & \begin{tabular}{|l|l|}
0.004 \\
\end{tabular} & 425246.254 & -0.197 & 0.039 \\
\hline 125 & & & 4533983.382 & 0.016 & 0.000 & 425246.113 & -0.056 & 0.003 & 4533983.346 & 0.052 & 0.003 & 425246.227 & -0.170 & 0.029 \\
\hline 126 & & & 4533983.390 & 0.008 & 0.000 & 425246.089 & -0.032 & 0.001 & 4533983.355 & 0.043 & 0.002 & 425246.201 & -0.144 & 0.021 \\
\hline 127 & & & 4533983.398 & 0.000 & 0.000 & 425246.065 & -0.008 & 0.000 & 4533983.364 & 0.034 & 0.001 & 425246.174 & -0.117 & 0.014 \\
\hline 128 & & & 4533983.406 & -0.008 & 0.000 & 425246.042 & 0.015 & 0.000 & 4533983.373 & 0.025 & 0.001 & 425246.147 & -0.090 & 0.008 \\
\hline \multirow[t]{3}{*}{129} & & & 4533983.415 & -0.017 & 0.000 & 425246.018 & 0.039 & 0.002 & 4533983.382 & 0.016 & 0.000 & 425246.120 & -0.063 & 0.004 \\
\hline & & & & $\sum[[v v] \rrbracket$ & 1.326 & & $\Sigma Z[V v]]$ & 14.840 & & $\Sigma[[v v] \rrbracket$ & 1.305 & & $\sum[[v v] \rrbracket$ & 14.574 \\
\hline & & & & \multicolumn{2}{|c|}{$\mathrm{m} 0=0.187$} & & \multicolumn{2}{|r|}{$\mathrm{m} 0=0.625$} & & \multicolumn{2}{|r|}{$m 0=0.185$} & & \multicolumn{2}{|r|}{$\mathrm{m} 0=0.619$} \\
\hline
\end{tabular}

ve eşitlik (4) ile hesaplanan standart sapma değerleri (mo) sunulmaktadır.

$$
\mathrm{m}_{\mathrm{o}}=\sqrt{\sum[V V] / n}
$$

Tablo verilerinden görüldüğü gibi Klasik GPR yöntemi ile $X$ koordinat için hesaplanan standart sapma değeri 0,187 iken GPR/GPS Kombinasyon modelinin X koordinat için standart sapma değeri 0,0185 olarak hesaplanmıştır. Y koordinat için ise Klasik GPR yönteminde standart sapma değeri 0,625 iken GPR/GPS Kombinasyon modelinde bu değer 0,619 olarak hesaplanmaktadır. Her iki koordinat için eğimsiz kabul edilebilecek arazi koşullarında (ortalama eğim 2 derece) hesaplanan standart sapma değerleri birbirine yakın olmakla beraber GPR/GPS Kombinasyon modelinin standart sapma değeri Klasik GPR modeline göre daha düşüktür. Klasik GPR Modeli ve GPR/GPS Kombinasyon Modeli için nokta konum hatası Eşitlik 5 'te yerine konulduğunda sırasıyla 0,652 ve 0,646 değerleri elde edildi. Bu sonuçlara göre GPR/GPS Kombinasyon Modelinin Klasik GPR Modeline kıyasla konumsal olarak daha düşük bir standart sapma değerine sahip olmakla birlikte eğimsiz kabul edilebilecek arazi koşullarında her iki yöntemde de birbirine yakın sonuçlar elde edildiği söylenilebilir.

$\mathrm{m}_{(\mathrm{XY})}=\sqrt{((\operatorname{mo}(\mathrm{X}) 2+\mathrm{mo}(\mathrm{Y}) 2))}$
Tablo 5'te ise eğimli arazi için seçilen detay noktalarının gömülü deponun bilinen koordinatlarına göre standart sapma hesabı görülmektedir.

Eğimli arazi koşullarında seçilen 39 detay noktasının $X$ ve $Y$ koordinatları için standart sapma hesabı her iki model için de yapıldığında Klasik GPR yöntemi ile X koordinatı için hesaplanan standart sapma değeri 0,328 m iken, GPR/GPS Kombinasyon modelinin $X$ koordinat için standart sapma değeri $0,224 \mathrm{~m}$ olarak hesaplanmıştır. Aynı şekilde $Y$ koordinat için Klasik GPR Modelinde 0,775 m iken, GPR/GPS Kombinasyon Modelinde standart sapma değeri 0,561 m olarak hesaplanmaktadır. Her iki model için eğimli arazi koşullarında nokta konum hatası Eşitlik 5 ile hesaplandığında Klasik GPR Modeli için 0,842 m, GPR/GPS Kombinasyon modeli için 0,604 m değerleri elde edilmiştir.

Tablo 6 ve Tablo 7 incelendiğinde eğimli ve eğimsiz arazi koşulları için yapılan hesaplamalarda Klasik GPR Modelinin nokta konum hatası eğimsiz arazide 0,652 m iken ortalama eğimin 7 derece olduğu eğimli arazide 0,842 m'ye çıktğı görülmüştür. GPR/GPS Kombinasyon modelinde ise eğimsiz arazi koşullarındaki nokta konum hatası 0,646 $\mathrm{m}$ iken eğimli arazi koşulları için 0,604 m olarak hesaplandı. Bu değer GPR/GPS Kombinasyon modelinin standart sapmasının eğim farklılığından etkilenmediğini ortaya koymaktadır. 
Tablo 5. Eğimli arazide Klasik GPR ve GPR/GPS Modelleri için standart sapma hesabı.

Table 5. Standard deviation calcutaion for Classic GPR and GPR / GPS Combination Models on a slopy ground.

\begin{tabular}{|c|c|c|c|c|c|c|c|c|c|c|c|c|c|c|}
\hline NN & $\mathrm{xi}$ & yi & \begin{tabular}{|l|} 
Klasik GPR X \\
\end{tabular} & $-d x$ & $-d x^{2}$ & \begin{tabular}{|l|} 
Klasik GPR Y \\
\end{tabular} & $-d y$ & $-d y^{2}$ & GPR/GPS X & $-d x$ & $-d x^{2}$ & GPR/GPSY & - dy & $-d y^{2}$ \\
\hline Ümit Değer & 4533997.759 & 425215.210 & & & & & & & & & & & & \\
\hline 1512 & & & 4533997.897 & -0.138 & 0.019 & 425214.938 & 0.272 & 0.074 & 4533997.759 & 0.000 & 0.000 & 425215.210 & 0.000 & 0.000 \\
\hline 1513 & & & 4533997.906 & -0.147 & 0.022 & 425214.914 & 0.295 & 0.087 & 4533997.769 & -0.010 & 0.000 & 425215.185 & 0.025 & 0.001 \\
\hline 1514 & & & 4533997.914 & -0.156 & 0.024 & 425214.891 & 0.319 & 0.102 & 4533997.779 & -0.020 & 0.000 & 425215.160 & 0.050 & 0.003 \\
\hline 1515 & & & 4533997.923 & -0.164 & 0.027 & 425214.867 & 0.343 & 0.117 & 4533997.789 & -0.030 & 0.001 & 425215.135 & 0.075 & 0.006 \\
\hline 1516 & & & 4533997.932 & -0.173 & 0.030 & 425214.844 & 0.366 & 0.134 & 4533997.799 & -0.040 & 0.002 & 425215.109 & 0.100 & 0.010 \\
\hline 1517 & & & 4533997.941 & -0.182 & 0.033 & 425214.820 & 0.390 & 0.152 & 4533997.809 & -0.050 & 0.002 & 425215.084 & 0.125 & 0.016 \\
\hline \begin{tabular}{|l|}
1518 \\
\end{tabular} & & & 4533997.950 & -0.191 & 0.037 & 425214.797 & 0.413 & 0.171 & 4533997.819 & -0.060 & 0.004 & 425215.059 & 0.151 & 0.023 \\
\hline \begin{tabular}{|l|}
1519 \\
\end{tabular} & & & 4533997.959 & -0.200 & 0.040 & 425214.773 & 0.437 & 0.191 & 4533997.829 & -0.070 & 0.005 & 425215.034 & 0.176 & 0.031 \\
\hline 1520 & & & 4533997.968 & -0.209 & 0.044 & 425214.750 & 0.460 & 0.212 & 4533997.839 & -0.080 & 0.006 & 425215.009 & 0.201 & 0.040 \\
\hline 1521 & & & 4533997.977 & -0.218 & 0.047 & 425214.726 & 0.484 & 0.234 & 4533997.849 & -0.090 & 0.008 & 425214.984 & 0.226 & 0.051 \\
\hline 1522 & & & 4533997.985 & -0.227 & 0.051 & 425214.703 & 0.507 & 0.257 & 4533997.859 & -0.100 & 0.010 & 425214.959 & 0.251 & 0.063 \\
\hline 1523 & & & 4533997.994 & -0.236 & 0.055 & 425214.679 & 0.531 & 0.282 & 4533997.869 & -0.110 & 0.012 & 425214.934 & 0.276 & 0.076 \\
\hline \begin{tabular}{|l|l|}
1524 \\
\end{tabular} & & & $\begin{array}{l}4533998.003 \\
\end{array}$ & -0.244 & 0.060 & 425214.656 & 0.554 & 0.307 & 4533997.879 & -0.120 & 0.014 & 425214.909 & 0.301 & 0.091 \\
\hline 1525 & & & 4533998.012 & -0.253 & 0.064 & 425214.632 & 0.578 & 0.334 & 4533997.889 & -0.130 & 0.017 & 425214.884 & 0.326 & 0.106 \\
\hline 1526 & & & 4533998.021 & -0.262 & 0.069 & 425214.609 & 0.601 & 0.361 & 4533997.899 & -0.140 & 0.020 & 425214.858 & 0.351 & 0.123 \\
\hline 1527 & & & 4533998.030 & -0.271 & 0.074 & 425214.585 & 0.625 & 0.390 & 4533997.909 & -0.150 & 0.022 & 425214.833 & 0.376 & 0.142 \\
\hline 1528 & & & 4533998.039 & -0.280 & 0.079 & 425214.562 & 0.648 & 0.420 & 4533997.919 & -0.160 & 0.026 & 425214.808 & 0.402 & 0.161 \\
\hline 1529 & & & 4533998.048 & -0.289 & 0.084 & 425214.538 & 0.672 & 0.451 & 4533997.929 & -0.170 & 0.029 & 425214.783 & 0.427 & 0.182 \\
\hline \begin{tabular}{|l|}
1530 \\
\end{tabular} & & & 4533998.057 & -0.298 & 0.089 & 425214.515 & 0.695 & 0.483 & 4533997.939 & -0.180 & 0.032 & 425214.758 & 0.452 & 0.204 \\
\hline \begin{tabular}{|l|}
1531 \\
\end{tabular} & & & 4533998.066 & -0.307 & 0.094 & 425214.491 & 0.718 & 0.516 & 4533997.949 & -0.190 & 0.036 & 425214.733 & 0.477 & 0.227 \\
\hline 1532 & & & 4533998.075 & -0.316 & 0.100 & 425214.468 & 0.742 & 0.550 & 4533997.959 & -0.200 & 0.040 & 425214.708 & 0.502 & 0.252 \\
\hline 1533 & & & 4533998.084 & -0.325 & 0.106 & 425214.445 & 0.765 & 0.586 & 4533997.969 & -0.210 & 0.044 & 425214.683 & 0.527 & 0.278 \\
\hline 1534 & & & 4533998.093 & -0.334 & 0.112 & 425214.421 & 0.789 & 0.622 & 4533997.979 & -0.220 & 0.048 & 425214.658 & 0.552 & 0.305 \\
\hline 1535 & & & 4533998.102 & -0.343 & 0.118 & 425214.398 & 0.812 & 0.660 & 4533997.989 & -0.230 & 0.053 & 425214.633 & 0.577 & 0.333 \\
\hline 1536 & & & 4533998.111 & -0.352 & 0.124 & 425214.374 & 0.836 & 0.698 & 4533997.999 & -0.240 & 0.058 & 425214.608 & 0.602 & 0.363 \\
\hline 1537 & & & 4533998.120 & -0.361 & 0.130 & 425214.351 & 0.859 & 0.738 & 4533998.009 & -0.250 & 0.062 & 425214.582 & 0.627 & 0.394 \\
\hline 1538 & & & 4533998.129 & -0.370 & 0.137 & 425214.327 & 0.882 & 0.779 & 4533998.019 & -0.260 & 0.067 & 425214.557 & 0.652 & 0.426 \\
\hline 1539 & & & 4533998.138 & -0.379 & 0.144 & 425214.304 & 0.906 & 0.820 & 4533998.029 & -0.270 & 0.073 & 425214.532 & 0.678 & 0.459 \\
\hline 1540 & & & 4533998.147 & -0.388 & 0.151 & 425214.281 & 0.929 & 0.863 & 4533998.039 & -0.280 & 0.078 & 425214.507 & 0.703 & 0.494 \\
\hline 1541 & & & 4533998.156 & -0.397 & 0.158 & 425214.257 & 0.953 & 0.907 & 4533998.049 & -0.290 & 0.084 & 425214.482 & 0.728 & 0.530 \\
\hline 1542 & & & 4533998.165 & -0.406 & 0.165 & 425214.234 & 0.976 & 0.953 & 4533998.059 & -0.300 & 0.090 & 425214.457 & 0.753 & 0.567 \\
\hline 1543 & & & 4533998.174 & -0.415 & 0.172 & 425214.210 & 0.999 & 0.999 & 4533998.069 & -0.310 & 0.096 & 425214.432 & 0.778 & 0.605 \\
\hline \begin{tabular}{|l|l|}
1544 \\
\end{tabular} & & & 4533998.183 & -0.424 & 0.180 & 425214.187 & 1.023 & 1.046 & 4533998.079 & -0.320 & 0.102 & 425214.407 & 0.803 & 0.645 \\
\hline 1545 & & & 4533998.192 & -0.433 & 0.188 & 425214.164 & 1.046 & 1.094 & 4533998.089 & -0.330 & 0.109 & 425214.382 & 0.828 & 0.686 \\
\hline 1546 & & & 4533998.201 & -0.442 & 0.196 & 425214.140 & 1.070 & 1.144 & 4533998.099 & -0.340 & 0.115 & 425214.357 & 0.853 & 0.728 \\
\hline 1547 & & & 4533998.210 & -0.451 & 0.204 & 425214.117 & 1.093 & 1.195 & 4533998.109 & -0.350 & 0.122 & 425214.332 & 0.878 & 0.771 \\
\hline 1548 & & & 4533998.219 & -0.460 & 0.212 & 425214.093 & 1.116 & 1.246 & 4533998.119 & -0.360 & 0.129 & 425214.306 & 0.903 & 0.816 \\
\hline 1549 & & & 4533998.228 & -0.469 & 0.220 & 425214.070 & 1.140 & 1.299 & 4533998.129 & -0.370 & 0.137 & 425214.281 & 0.928 & 0.862 \\
\hline \multirow[t]{3}{*}{1550} & & & 4533998.237 & -0.479 & 0.229 & 425214.047 & 1.163 & 1.353 & 4533998.138 & -0.380 & 0.144 & 425214.256 & 0.954 & 0.909 \\
\hline & & & & $\sum[[V v] \rrbracket$ & 4.086 & & E[lvV]I] & 22.826 & & E[IVV]I] & 1.899 & & E[IVV]I] & 11.976 \\
\hline & & & & & $\mathrm{m} 0=0.328$ & & & $\mathrm{~m} 0=0.775$ & & & $\mathrm{mo}=0.224$ & & & $\mathrm{~m} 0=0.561$ \\
\hline
\end{tabular}

Tablo 6. Standart sapma hesapları özet tablosu.

Table 6. Summary of standard deviation calculations.

\begin{tabular}{|l|l|l|l|l|}
\hline & Klasik GPR $(\mathbf{X}) \mathbf{m}_{0}$ & Klasik GPR (Y) $\mathbf{m}_{0}$ & GPR/GPS Kom.(X) $\mathbf{m}_{0}$ & GPR/GPS Kom.(Y)m $\mathbf{m}_{0}$ \\
\hline EĞiMLi ARAZi & 0,328 & 0,775 & 0,224 & 0,561 \\
\hline EĞiMSiz ARAZi & 0,187 & 0,625 & 0,185 & 0,619 \\
\hline
\end{tabular}

Tablo 7. Konum hatası özet tablosu.

Table 7. Horizontal positioning errors.

\begin{tabular}{|l|l|l|}
\hline & Klasik GPR (XY) $\mathbf{m}_{\mathbf{0}}$ & GPR/GPS Kom. (XY) $\mathbf{m}_{\mathbf{0}}$ \\
\hline EĞiMLi ARAZi & 0,842 & 0,604 \\
\hline EĞiMSiz ARAZi & 0,652 & 0,646 \\
\hline
\end{tabular}

Eşitlik 6 ile doğruluk analizi yapıldığında;

$\frac{m o(\text { Klasik GPR })-m o(G P R-G P S)}{\text { mo }(\text { Klasik GPR })} X 100$

GPR/GPS Kombinasyon modelinin Klasik GPR yöntemine kıyasla eğimsiz arazi koşullarında modellemeye olan katkısı \% 0,89 ve eğimli arazi koşullarında \% 28,20 olarak hesaplanmaktadır. Bu analizle GPR/GPS Kombinasyon Modelinin Klasik GPR Modeline göre daha başarılı olduğu istatistiksel olarak kanıtlanmıştır.

\section{Sayısal Analiz 2:}

Önceki 3 örnekte de GPR/GPS Kombinasyon Modelinin daha başarılı olduğu görülmüştür. Bu bölümde 44 ölçüm profili ve her iki modele ait detay noktalarının tamamı kullanarak gömülü objenin bilinen boyutları ile karşılaştırılmıştır. Araştırmaya konu olan su depoları $20 \mathrm{~m}$ uzunluğunda ve $10 \mathrm{~m}$ genişliğindedir. Temel kot seviyesi -0,20 m iken betonarme duvar üst kotu 3,45 m'dir. Temel ampartmanı duvar sınırlarından itibaren $0,5 \mathrm{~m}$ çaIışma payı ile imal edilmiş ampartman seviyesi ve onun altında yer alan beton kırmataş kesiti ise 0,5 m'dir. Dolayısıyla 1 depo için hacim hesabı yapılacak olursa;

$20 \mathrm{~m}$ (uzunluk) $\times 10 \mathrm{~m}$ (genişlik) $\times(3,45+0,2=3,65)$ (yükseklik)= $730 \mathrm{~m}^{3}$

$(20+0,5+0,5=21)$ m Ampartman uzunluğu x $(10+05+05=11)$ metre Ampartman Genişliği x 0,5 m temel derinliği (Temel Betonu + Kırmataş Kesiti) $=115,5 \mathrm{~m}^{3}$

yani 1 depo için toplam hacim $=845,5 \mathrm{~m}^{3}$ tür.

Bilinen hacim değerinin farklı eğim gruplarında her iki modelle hangi doğrulukla belirlenebileceğini araşttrabilmek amacıyla aşağıdaki işlem adımları uygulanmıştır.

1) Klasik GPR, GPR/GPS Modeli için yüzey detay noktaları ve zemin detay noktaları için TIN modeller oluşturuldu.

2) Nokta dosyaları üzerinde üçgenleme (Triangulation) işlemi uygulanarak 0,5 m aralıklarla grid model oluşturuldu. 
3) Grid noktalar kullanılarak yeniden üçgenleme (Triangulation) işlemi yapıldı.

4) Depo sınırları grid modeller üzerine işaretlenerek enkesit güzergahı her 3 depo için de ayrı ayrı belirlendi.

5) Klasik GPR, GPR/GPS Kombinasyon Modelleri kullanılarak her 3 su deposu için yüzey ve zemin enkesitleri 1 metre aralıklarla oluşturuldu.

6) NetCAD yazılımı NetSURF modülü yardımıyla enkesitlerden kübaj hesabı yapıldı (Tablo 8).

Tablo 8. Klasik GPR ve GPR/GPS Modelleri - Kübaj hesapları özet listesi. Table 8. Determining the volumes of earth masses from classic GPR and GPR/GPS combination models.

\begin{tabular}{|l|l|l|l|l|}
\hline Model & Klasik GPR & GPR/GPS Kombinasyonu & Hata (Illasik GPR) & Hata (IGPR/GPS) \\
\hline DEPO 1 & $1664,318 \mathrm{~m}^{3}$ & $\mathbf{1 5 7 5 , 4 0 5 \mathrm { m } ^ { 3 }}$ & $+819 \mathrm{~m}^{3}$ & $\mathbf{+ 7 3 0 \mathrm { m } ^ { 3 }}$ \\
\hline DEPO 2 & $1341,248 \mathrm{~m}^{3}$ & $\mathbf{1 2 7 1 , 8 4 \mathrm { m } ^ { 3 }}$ & $+493 \mathrm{~m}^{3}$ & $\mathbf{+ 4 2 7} \mathrm{m}^{\mathbf{3}}$ \\
\hline DEPO 3 & $1499,946 \mathrm{~m}^{3}$ & $\mathbf{1 4 5 7 , 0 6 1} \mathrm{m}^{3}$ & $+654 \mathrm{~m}^{3}$ & $\mathbf{+ 6 1 2} \mathbf{m}^{\mathbf{3}}$ \\
\hline
\end{tabular}

1 ve 3 No'lu depoların 2 cephesi eğimli bir topografya altında gömülü iken 2 No'lu deponun yalnızca 1 cephesi eğimlidir. 1 ve 3 No'lu depoların arasında yer alan ve aynı zamanda yatay profillerin düzlemsel olduğu bölgede bulunan 2 No'lu depo için her iki modelde de gömülü su deposunun gerçek hacim değeri olan 845 m3 değerine en yakın hacim değerleri hesaplanmıştır. Genel olarak Tablo 8'deki veriler göz önüne alındığında GPR/GPS Kombinasyon yönteminin gömülü obje modellemesinde Klasik GPR yöntemine kıyasla daha az hata payına sahip olduğu görülmektedir.

\section{Sonuç ve Tartişma}

Görsel analiz 1 ve 2'de GPR/GPS Kombinasyon Modelinin depo sınırlarını daha doğru ifade ettiği görülmüştür. Özellikle eğimli arazi koşullarında Klasik GPR Modeli ile elde edilen 0,842 standart sapma değerine karşılık GPR/GPS Kombinasyon Modeli için aynı ortam koşullarında elde edilen standart sapma değeri 0,604 olarak hesaplanmıştır. Böylelikle modelin başarısı "Sayısal Analiz 1" ile istatistiksel olarak kanıtlanmıştı. Sayısal Analiz 2'de ise her iki model için tüm detay noktaları kullanılarak oluşturulan $3 \mathrm{~B}$ modeller gömülü objenin bilinen hacim değeri ile kıyaslanmış, GPR/GPS Kombinasyon Modelinin Klasik GPR Metoduna kıyasla eğimsiz arazi koşullarında \%0,89 ve eğimli arazi koşullarında \%28,20 daha başarılı olduğu matematiksel anlamda da ispat edilmiştir.

Çalışmanın gerçekleştirildiği alanda ortalama eğim değeri 7 derecedir. Daha yüksek kot farklılıklarının bulunduğu bir arazide yapılacak gömülü obje araştırmasında GPR/GPS Kombinasyonunun modelleme başarısı daha net görülebilir.

GPR/GPS Kombinasyon Metodu; Arkeolojik araşttrmalar, hasarsız karot, yol çalışmalarında gömülü tesisatların belirlenmesi, mayın tespiti gibi araştırma konularında koordinatlı ve daha doğru değerlerle gömülü objeyi tespit etme veya modelleme olanağı sunmaktadır.

Gömülü objenin daha doğru konumlandırılması ise; yöntemin gömülü objeye daha az kazı yapılarak ulaşılabilmesine imkan tanıması, daha az iş gücü gerektirmesi ve dolayısıyla daha eko- nomik olduğu anlamına gelmektedir.

Gömülü objenin Ülke Koordinat Sisteminde (UTM) modellenebilmesi; verilerin Coğrafi Bilgi Sistemlerine altlık oluşturabilmesine ve koordinatlı yer alt haritalarının üretilmesine imkan tanımaktadır.

\section{Kaynakça}

Alp, I. Gelişli,K. Yılmaz, A.O., Kaya, R., Çavuşoğlu, i., (2003). Mermer Işletmeciliğinde Yer Radarı Uygulamaları.

Conyers, L.B., 2013. Ground-Penetrating Radar for Archaeology, 3rd ed.; Rowman and Littlefield Publishers, Alta Mira Press: Latham, MD, USA, ISBN: 9780759123496.

Dannowsky, G.,and Yaramancl, U., 1999. Estimation of water content ant porosity using combined radar and geoelectric measurements. European Journal of Environmental and Engineering Geophysics, 4,71-85.

Davis, J.L.,and Annan, A.P., 1989. Ground Penetrating Radar for high resolution mapping of soil and rock stratigraphy. Geophysical Prospecting, 37, 531-551.

Goodman D., Piro S., 2013. GPR remote sensing in Archeology, Geotechnologies and the environment, Springer Heidelberg New York Dordrecht London, ISBN 978-3-642-31857-3 (eBook).

Grandjean, G.,andGourry, J.C., 1999. GPR data processing for 3D fracture mapping in a marble quarry (Thassos, Greece). Journal of Applied Geophysics, 36, 19-30.

Green, A.,Gross, R., Holliger, K., Horstmeyer, H., andBaldwin, J., 2003. Results of 3-D georadar surveying and trenching the San Andreas fault nearits northern land ward limit. Tectonophyisics, 368, 7-23.

Harrari, Z., 1996. Ground penetrating radar (GPR) for imaging stratigrafic features and graund water in sand dunes. Journal of Applied Geophysics, 36, 43-52.

F. Lehmann and G. Green, 1999 -Semiautomated georadar data acquisition in three-dimensions. Geophysics 64 (3):719-731

J. Sun and A. Young, 1995 - Scattering in ground-penetrating radar data. Geophsica 6 (5): 1378-1385.

Jol H. M., 2009. Ground Penetrating Radar Theory and Applications, Elsevier Books, Oxford, UK.

Persico R., 2014. Introduction to Ground Penetrating Radar (Inverse Scattering and Data Processing)- Wiley-IEEE Press - ISBN 978-1118-30500-3, s. xiii

Sandmeier, K.J., 2004. Scientific Software, REFLEX-W ver.3.5 program for processing and interpretation of reflection and transmission data.

Van Dam, R. I And W. Schlager, 2000 - Identifyingcauses of ground-penetrating radar reflectionsusing time-domain reflectometryandsedimentologicalanalysis. Sedimentology 47: 435-449. 
EK 1

$d y=+$ ve $d x=+$ ise; Birinci Bölgededir $\left(0^{\circ}-90^{\circ}\right) ; \arctan (d y / d x)$ değeri Açıklık Açısını ifade eder.

$d y=+$ ve $d x=-$ ise; İkinci Bölgededir $\left(90^{\circ}-180^{\circ}\right), 180^{\circ}$ $\arctan (\mathrm{dy} / \mathrm{dx}$ ) ile hesaplanan değer Açıklık Açısını ifade eder.

$d y=-$ ve dx= - ise; Üçüncü Bölgededir $\left(180^{\circ}-270^{\circ}\right), 180^{\circ}+\arctan$ (dy/dx) eşitliği Açıkıı Açısını ifade eder.

$d y=-$ ve $d x=+$ ise; Dördüncü Bölgededir $\left(270^{\circ}-360^{\circ}\right), 360^{\circ}$ - arc$\tan (d y / d x)$ eşitliği Açıklık Açısını ifade eder.

\begin{tabular}{|l|l|}
\hline Trace No: & A \\
\hline Tarih: & B \\
\hline Saat: & C \\
\hline YGPSKoordinatı: & D \\
\hline XGPS Koordinatı: & F \\
\hline ZGPS (2) Koordinatı: & H \\
\hline Anten Yüksekliği: & J \\
\hline Seçilen Detay Noktası Derinlik Değeri: & N \\
\hline Seçilen Detay Noktasının Profil Mesafesi: & O \\
\hline
\end{tabular}

dy (Y Koordinatları Farkının Hesaplanması)

EXCEL FORMÜLÜ: ALAN_P = D2-D\$2

ACCESS (SQL) KODU: dy: [GPS (2)].[enlem]DLookUp("[enlem]";"GPS (2)";"[trace] = 2")

dx (X Koordinatları Farkının Hesaplanması)

EXCEL FORMÜLÜ: ALAN_Q= F3-F\$2

ACCESS (SQL) KODU: dx: [boylam]-DLookUp("[boylam]";"GPS (2)";"[trace] = 2")

$\operatorname{Arctan}(d y / d x)$ Değerinin Hesaplanması (Derece)

EXCEL: ALAN_R $=$ ATAN $(P 2 / Q 2) * 180 /(P i())$

ACCESS (SQL) KODU: dy/dx: Atn([dy]/[dx])*180/(4*Atn(1))

Açıklık Açısı Hesabı

EXCEL:ALAN_S=EĞER(VE(P2<0;Q2>0);R2+360;EĞER(VE(P2>0;Q $2<0) ; \mathrm{R} 2+180 ; \mathrm{EĞER}(\mathrm{VE}(\mathrm{P} 2>0 ; \mathrm{Q} 2>0) ; \mathrm{R} 2 ; \mathrm{EGKER}(\mathrm{VE}(\mathrm{P} 2<0 ; \mathrm{Q} 2<0) ; \mathrm{R}$ $2+180 ; " "))))$

ACCESS (SQL) KODU: acıklık_acıSI: IIf(([dy]>0 And $[d x]<0) ;[d y / d x]+180 ;$ IIf $(([d y]>0$ And $[d x]>0) ;[d y / d x] ; \| f(([d y]<0 A n d[d x]<0) ;[d y / d x]+180 ; \| f(([d y]<0$ And $[d x]>0) ;[d y / d x]+360)))$ )

\section{EK 2}

YGPS koordinatının tüm detay noktaları için hesaplanması:

EXCEL FORMÜLÜ: ALAN_T =EĞER(D1-

$\left.\mathrm{D} 2=0 ; \mathrm{D} 2+\operatorname{Sin}(\mathrm{S} 2 * \mathrm{Pi}() / 180)^{*}\left(\mathrm{O} 2-\left(\left((\mathrm{P} 2)^{\wedge} 2+(\mathrm{Q} 2)^{\wedge} 2\right)^{\wedge} 0.5\right)\right) ; \mathrm{D} 2\right)$

ACCESS (SQL) KODU: YGPS:IIf(DLookUp("[GPS

(2)].[enlem]";"GPS (2)";"[trace]=" \& [trace]-1)-

DLookUp("[enlem]";"GPS (2)";"[trace]=" \&

[trace] $)=0 ;[$ enlem $]+\left([\right.$ mesafe $\left.]-\left([d y]^{\wedge} 2+[d x]^{\wedge} 2\right)^{\wedge} 0.5\right) * \operatorname{Sin}([$ acıklık_acısı $\left.{ }^{*}\left(4^{*} \operatorname{Atn}(1) / 180\right)\right) ;[$ enlem])

XGPS koordinatının tüm detay noktaları için hesaplanması:

EXCEL FORMÜLÜ: ALAN_U =EĞER(F1-

$\left.\mathrm{F} 2=0 ; \mathrm{F} 2+\operatorname{COS}(\mathrm{S} 2 * \mathrm{P} \mathrm{i}() / 180)^{*}\left(\mathrm{O} 2-\left((\mathrm{P} 2)^{\wedge} 2+(\mathrm{Q} 2)^{\wedge} 2\right)^{\wedge} 0.5\right) ; \mathrm{F} 2\right)$

ACCESS (SQL) KODU: XGPS: IIf(DLookUp("[GPS

(2)].[boylam]";"GPS (2)";"[trace]=" \& [trace]-1)-

DLookUp("[boylam]";"GPS (2)";"[trace]=" \& [trace])=0;[boylam $]+\left([\text { mesafe }]-\left([\mathrm{dy}]^{\wedge} 2+[\mathrm{dx}]^{\wedge} 2\right)^{\wedge} 0.5\right)^{*} \operatorname{Cos}\left([\text { acıklık_acısı }]^{*}\left(4^{*} \mathrm{~A}\right.\right.$ $\operatorname{tn}(1) / 180)) ;[$ boylam])

Gömülü Obje İçin Z(elipsoidal) Koordinatlarının Üretilmesi

EXCEL FORMÜLÜ: ALAN_AU=H2-J2-N2 